Página inicial: 259 - Página final: 293

TIPO DE ARTÍCULO: de Reflexión

\title{
DE LOS BIENES COMUNES AL BIEN COMÚN DE LA HUMANIDAD ${ }^{1 *}$.
}

OF THE COMMON GOOD TO THE COMMON GOOD OF HUMANITY.

Recibido: Febrero 2013 Revisado: Octubre 2013 Aceptado: Diciembre 10 de 2013

Por: François Houtart ${ }^{1}$.

\section{RESUMEN.}

No hay lugar en el mundo, donde un profundo malestar se manifiesta frente al aumento de las brechas sociales, al irrespeto a la justicia, al desempleo de los jóvenes, a los abusos de poder, a la destrucción de la naturaleza. Una nueva ola de movimientos sociales se ha desarrollado. Los Foros sociales permitieron su globalización. Una conciencia social colectiva crece: no se puede seguir así. El tipo de desarrollo económico que vivimos actualmente, con sus consecuencias políticas, culturales y sicológicas, es el origen de los desequilibrios. Al mismo tiempo, la necesidad de soluciones se impone de manera urgente. Es el momento de plantear nuevas orientaciones y no solamente adaptaciones. Reunir fuerzas para actuar y pensar por este fin, es una prioridad. Es por esto que, junto a la iniciativa del Referéndum sobre el agua (uno de los bienes comunes) en Italia, la Fundación Rosa Luxemburgo tomó la decisión de organizar una Conferencia sobre el concepto del Bien Común de la Humanidad, para promover una reflexión sobre los vínculos entre las dos nociones y de integrar las reivindicaciones y las luchas sociales para un cambio de sociedad, escenario en el que se enmarca éste artículo.

\section{PALABRAS CLAVE.}

crisis de civilización, paradigma, bienes comunes, movimientos sociales.

\section{ABSTRACT.}

There is no place in the world, where a deep discomfort manifests against the increase of the social gaps, to the disrespect for justice, to the unemployment of young people, the abuse of power, and the destruction of nature. A new wave of social movements has been developed. The social forums allowed its globalization. A collective social conscience grows: we cannot continue like this. The kind of economic development that we go thorough today, with its political, psychological, and cultural consequences is the source of the imbalances. At the same time, the need for solutions is essential urgently. It is time to consider new directions and not only adaptations. Gathering forces to act and to think for this purpose, is a priority. This is why, along with the initiative of the Referendum on the water (one of the Common Good) in Italy, the Rosa Luxembourg Foundation made the decision to organize a Conference on the concept of the Common Good of Humanity, to promote a reflection on the links between the two concepts and to integrate the demands and social struggles for a change of society, scenario in which this article is framed.

\section{KEY WORDS.}

Crisis of Civilization; Paradigm; the Common Good; and Social Movements.

\footnotetext{
1 Sacerdote católico y sociólogo marxista belga, fundador del Centro Tricontinental (CETRI) que funciona en la Universidad Católica de Lovaina y de la revista "Alternatives Sud". Es una figura reconocida del movimiento altermundista. Asesor del CELAM. Francois.houtart@iaen.edu.ec.
} 


\section{Introducción.}

¿Por qué asociar la noción de "bienes comunes" al concepto de "Bien común”?

La defensa de los "bienes comunes" es hoy una reivindicación fuerte de muchos movimientos sociales. Ella incluye tanto elementos indispensables para la vida, como el agua y las semillas, como los "servicios públicos" hoy en día desmantelados por las políticas neoliberales, tanto en el Sur como en el Norte. Esta lucha consiste en una oposición a la ola de privatizaciones que afectaron una gran parte de las redes públicas, desde los ferrocarriles, la electricidad, el agua, los transportes, la telefonía, las selvas, los ríos, las tierras, hasta la salud y la educación. Lo que se llamaba, antes del capitalismo en Inglaterra, los "commons", se estrechó progresivamente para dar lugar a un sistema económico transformando el conjunto de la realidad en mercancía, paso necesario para la acumulación del capital y hoy día acentuado por la hegemonía del capital financiero. El common land (tierra comunal) fue considerado como wasted land (desperdiciado) y todo uso no capitalista de la tierra significaba un no-uso (Michaël Brie, 2011).

Está claro que la revalorización de los "bienes comunes", en cualquiera de sus formas formas (nacionalización u otra forma de control colectivo), constituye un objetivo fundamental para salir de una larga época donde la lógica económica había puesto el acento sobre lo privado y lo individual para promover el desarrollo de las fuerzas productivas y la emancipación de la iniciativa personal hasta eliminar la mayor parte de lo público de sus objetivos. Hemos llegado a la mercantilización aún de la vida humana y de su reproducción. Esta lógica económica instrumentalizó el campo político, como se evidenció durante la crisis financiera de los años 2008 y los años siguientes con las operaciones de salvataje del sistema bancario, al nacionalizarlo y dejándolo en manos de quienes provocaron la crisis (a menos que en algún momento se condene a los delincuentes). Tales políticas desembocaron en medidas estatales de austeridad, haciendo pagar a las poblaciones el peso de la crisis, siguiendo sin embargo las politicas neoliberales.

La defensa de los servicios públicos y de los "bienes comunes" se ubica en el conjunto de las resistencias a estas politicas, pero éstas se arriesgan a ser solamente combate de retaguardia, si no se sitúan en un cuadro más amplio, el del "Bien Común de la Humanidad", del cual forman parte. De hecho, el restablecimiento de ciertos sectores de los servicios públicos, puede ser recomendada aún por organismos como el Banco Mundial. Varios empresarios piensan lo mismo, cuando después de la ola de privatizaciones, se constató que no todo era tan rentable, como se había pensado.

Abordar este concepto puede parecer bastante teórico, frente a preocupaciones sociales y políticas. Sin embargo éste puede ser un instrumento de trabajo concreto bastante útil, para afrontar situaciones contemporáneas, como las diversas crisis y también la convergencia de las resistencias y de las luchas contra un sistema destructor de la naturaleza y de las sociedades. Se trata de realidades muy concretas, en primer lugar con la solidaridad, que se desvanece frente a la competitividad y al individualismo, pero también se trata del altruismo, del respeto del otro y de la naturaleza, de la ternura, en breve de lo que constituye lo humano. 
Empezaremos este trabajo por un análisis de la crisis y sus múltiples facetas, mostrando su carácter sistémico, lo que plantea el problema de los bienes comunes y del Bien común en nuevos términos. Continuaremos con la necesidad de una revisión de los paradigmas de la vida colectiva de la humanidad sobre el planeta, insistiendo en los aspectos prácticos de esta revisión en las políticas económicas y sociales, nacionales e internacionales y terminando por una propuesta de Declaración Universal del Bien Común de la Humanidad.

El Bien común es lo compartido por todos los seres humanos, hombres y mujeres. Ya Aristóteles en su obra sobre La Política, estimaba que ninguna sociedad puede existir sin algo en común, a pesar de opinar que lo común debía ser reducido al mínimo. Sin embargo, (en este documento) no vamos desarrollar aquí el aspecto filosófico de la cuestión; queremos más bien privilegiar un enfoque sociológico, es decir (las condiciones) el estudio del contexto en el cual el Bien Común de la Humanidad se plantea hoy. El concepto se distingue del de "bienes comunes" por su carácter más general, implicando los fundamentos de la vida colectiva de la humanidad en el planeta: la relación con la naturaleza, la producción de la vida, la organización colectiva (la política) y la lectura, la evaluación y la expresión de lo real (la cultura). No se trata tampoco de un patrimonio, como en el caso de los "bienes comunes", sino de un estado (bien estar, bien vivir) resultado del conjunto de los parámetros de la vida de los seres humanos, hombres y mujeres, en la tierra. Se distingue también de la noción de "bien común", como diferente de "bien individual", como se define en la construcción de un Estado, es decir la res publica, aún si el concepto de "bienes públicos mundiales" ha sido introducido por el PNUD en su informe de 1999. De hecho se trata de la producción y de la reproducción de la vida a escala de la humanidad. Finalmente el Bien Común de la Humanidad es la vida y su reproducción.

Fue Riccardo Petrella quien afirmó la necesidad de reconstruir la noción del Bien Común, frente al neoliberalismo dominante y a la dominación del mercado (1998), basando su perspectiva sobre un nuevo "contrato social mundial" del tener, de la cultura, de la democracia y de la tierra. Se trata de formular los principios y establecer las reglas, las instituciones, la cultura.

Evidentemente el concepto de Bien Común de la Humanidad incluye las nociones de bienes comunes y de "bien común" en sus traducciones concretas. Si empezamos la reflexión por la crisis actual, es por la simple razón que ella está poniendo en peligro, no solamente a los bienes comunes o a la noción de "Bien Común", sino a la supervivencia misma del género humano en la tierra y la posibilidad para esta última de regenerarse a causa de la actividad predatoria humana, es decir, el Bien Común de la Humanidad, lo que exige una revisión con urgencia. La dinámica de acumulación en los espacios territoriales empezó a poner en peligro la preservación de los "bienes comunes"; hoy en dia, el acaparamiento de las tierras en los continentes del Sur para el desarrollo de la agricultura industrial (en particular los agro-combustibles) y la extracción de los minerales, constituye una nueva etapa de los enclosures. La misma lógica contaminó la idea de Bien Común en el centro y en las periferias del capitalismo. Prevalece la muerte y no la vida. A fin de llegar a soluciones, debemos replantear el problema desde sus raíces, es 
decir redefinir lo que es el Bien Común de la Humanidad hoy en día. Por eso, en un primer momento, el carácter fundamental de la crisis será ilustrado por algunos de sus elementos principales.

\section{Las múltiples caras de la crisis}

Cuando más de 900 millones de seres humanos viven debajo de la línea de pobreza y que su número aumenta (PNUD, 2010), cuando cada 24 horas decenas de millares de personas mueren de hambre o de sus consecuencias, cuando desaparecen dia tras día etnias, modos de vida, culturas, poniendo el patrimonio de la humanidad en peligro, cuando la desigualdad entre hombres y mujeres se consolida en el sistema económico formal e informal, cuando el clima se deteriora, no se puede solamente hablar de crisis financiera coyuntural, aunque haya estallado de manera abrupta.

\section{Las diversas crisis}

\section{La crisis financiera y económica}

Cabe subrayar que las consecuencias sociales de la crisis financiera se sienten más allá de las fronteras de su propio origen y afecta a los fundamentos mismos de la economía. Desempleo, aumento del costo de la vida, exclusión de los más pobres, vulnerabilidad de las clases medias, amplian la lista de las víctimas en el mundo entero. No se trata solamente de un accidente en el recorrido, ni solamente de abusos cometidos por algunos actores económicos que requieren ser sancionados. Estamos confrontados a una lógica que atraviesa toda la historia económica de los últimos siglos (Fernand Braudel, 1969, Immanuel Wallerstein, 2000, István Mészarós, 2008, Wim Dierckxsens, 2011)). Crisis en desregulación, desregulación en crisis: este vaivén responde siempre a la presión de las tasas de ganancia: en aumento se desregula, en disminución se regula, pero siempre a favor de la acumulación del capital, definida como motor del crecimiento. Lo que se vive hoy en día no es entonces nuevo. No es la primera crisis del sistema financiero y muchos dicen que no será la última

La burbuja financiera creada durante los últimos decenios, gracias, entre otros, a nuevas tecnologias de información y de comunicaciones, ha sobredimensionado todos los datos del problema. Como se sabe, esta burbuja estalló con el problema de los subprimes en los Estados Unidos, es decir el endeudamiento insolvente de millones de personas, velado por una multiplicidad de productos financieros derivados (Reinaldo A. Carcanholo y Mauricio de S. Sabardini, 2009, 57). En los países industrializados, el consumo aumentaba más rápidamente que los ingresos (Joseph Stiglitz, 2010, 12). Sin embargo, el fenómeno era mucho más antiguo, desde el momento en que una economía virtual tomó la prioridad sobre la economía real, en otras palabras, cuando el capital financiero empezó a ser más provechoso que el capital productivo (Jorge Beinstein, 2009, 29). Uno de los orígenes del proceso fue la decisión del Presidente Nixon, en 1972, de desvincular el dólar del oro, lo que inicio nuevas politicas monetarias, en el cuadro de un crecimiento de la interdependencia económica internacional: la globalización (Joseph. Stiglitz, 22). 
El capitalismo ha conocido crisis financieras desde muy temprano. La primera fue al final del siglo XVIII y se renovaron en el curso de la historia. La última, a nivel mundial fue en los años 29-30, seguida, después de la segunda guerra mundial, por varias crisis regionales (México, Argentina, Asia, Rusia). La nueva crisis financiera mundial de 2008 desencadenó en los países del centro del sistema, una serie de políticas específicas: endeudamiento de los Estados, restricción de crédito, políticas de austeridad, etc. Aún los países del Sur fueron afectados, por la disminución de las exportaciones (China), de las remesas (América central y países andinos, Filipinas), aumento del precio del petróleo, etc. Estos países no fueron tan golpeados por el endeudamiento insolvente y muchos aprovecharon del alza de los precios de los recursos naturales, creando, sin embargo en materia de energia, un desequilibrio entre los productores o no productores de petróleo y en los alimentos, alzas de precios afectando a los más pobres de los consumidores, en particular, las mujeres.

La causa fundamental de la crisis financiera se encuentra en la lógica misma del capitalismo (Rémy Herrera y Paulo Nakatani, 2009, 39). Hacer del capital el motor de la economía, y de su acumulación lo esencial del desarrollo, lleva a la maximización del provecho. Si la financiarización de la economía favorece la tasa de ganancia y si la especulación acelera el fenómeno, la organización de la economía en su conjunto sigue este camino. Así, la primera característica de esta lógica: el aumento de la tasa de provecho en función de la acumulación del capital, se manifiesta con toda claridad en este proceso. Pero, un mercado capitalista no regulado lleva inevitablemente a la crisis. Y, como indica el informe de la Comisión de las Naciones Unidas, "Eso es una crisis macro-económica" (Joseph Stiglitz, 2010, 195).

Sin embargo, la diferencia principal con el contexto similar al de los años 30, es que el desequilibrio financiero y monetario actual se combina con otras crisis de otro tipo: alimentaria, energética, climática, todas, sin embargo, vinculadas a la misma lógica.

\section{La crisis alimentaria}

La crisis alimentaria tiene dos aspectos, uno coyuntural y un segundo, estructural. El primero se manifestó con el aumento súbito de los precios de los productos de alimentación en 2007 y 2008. Si, para explicar el fenómeno, existían algunas bases efectivas, como una cierta disminución de las reservas, la razón principal fue de orden especulativo, a la cual la producción de agro-carburantes no fue ajena (el etanol a partir del maíz en los Estados Unidos). Así, el precio del trigo en la bolsa de Chicago aumentó en un $100 \%$, el maíz en $98 \%$ y el etanol en 80 \%. Durante estos años una parte del capital especulativo se desplazó de otros sectores para invertirse en la producción alimentaria, en espera de provechos rápidos e importantes. En consecuencia, según el director general de la FAO, cada año, en 2008 y en 2009, más de 50 millones de personas descendieron bajo de la línea de pobreza y el total de gente viviendo en esta situación alcanzó en 2008 una cifra nunca conocida antes, de más de mil millones de personas. Tal situación fue claramente el resultado de la lógica del provecho, la ley capitalista del valor. 
El segundo aspecto es estructural. Se trata de la expansión, durante los últimos años del monocultivo, resultando en la concentración de las tierras, es decir en una verdadera contra-reforma agraria. La agricultura campesina o familiar se destruye en el mundo entero bajo el pretexto de su baja productividad. De hecho los monocultivos tienen una producción que puede ir hasta 500 y a veces $1000 \%$ más que la agricultura campesina en su estado actual. Sin embargo dos factores deben ser tomados en cuenta. El primero es la destrucción ecológica provocada por esta forma de producción. Se eliminan bosques, se contaminan los suelos y las aguas, hasta los ríos y el mar, por el uso masivo de productos químicos. Dentro de los próximos 50 o 75 años, se preparan los desiertos del futuro. Por otra parte, los campesinos son expulsados de sus tierras y son millones los que tienen que migrar hasta las ciudades, en los barrios marginales, agravando el peso de las tareas de las mujeres, provocando las crisis urbanas y aumentando la presión migratoria interna, como en el Brasil, o externa, como en muchos otros países del mundo.

Con los servicios públicos, la agricultura es una de las nuevas fronteras actuales del capital (Samir Amin, 2004), especialmente en tiempos de disminución relativa de la rentabilidad del capital productivo industrial y de la amplitud considerable tomada por el capital financiero, en búsqueda de fuentes de provecho. Últimamente se asistió a un fenómeno inédito: el acaparamiento de tierras por capitales privados y estatales. En el caso de África, particularmente producciones alimentarias o de agrocombustibles. Compañías como Daiwoo de Corea del Sur, obtuvo una concesión de 1.200.000 hectáreas de tierras en Madagascar por 99 años, lo que provocó una grave crisis política. Países como Libia y los Emiratos del Golfo hacen lo mismo en Mali y varios otros países africanos. Multinacionales europeas y norteamericanas de minería o de agro-energía aseguran la posibilidad de explotación de decenas de millones de hectáreas por períodos largos. Lo mismo hacen empresas estatales o privadas chinas.

Hay muy poca preocupación por los daños ecológicos y sociales, considerados como "externalidades", es decir como externos a los cálculos del mercado. Y ese es el segundo aspecto de la lógica del capitalismo, después de la tasa de ganancia. No es el capital el que soporta estos efectos negativos, sino las sociedades locales y los individuos. Eso siempre ha sido la línea de acción del capital, tanto en los países centrales, sin preocupación por la suerte de la clase obrera y en las periferias con el colonialismo, sin cuidado de la naturaleza ni de los modos de vida de las poblaciones. Es por todas estas razones que la crisis alimentaria, tanto en su aspecto coyuntural como estructural, está directamente vinculada con la lógica del capitalismo.

\section{La crisis energética}

Ésta va más allá de la explosión coyuntural de los precios del petróleo y es parte del agotamiento de los recursos naturales, sobreexplotados por el modelo de desarrollo capitalista. Una cosa está clara: la humanidad tendrá que cambiar la fuente de su energía en los 50 años que vienen, pasando de la energía fósil a otras fuentes. La utilización irracional de energía y el despilfarro de los recursos naturales, se manifestó especialmente después de la segunda guerra mundial y en particular con el "Consenso de Washington", es decir la liberalización generalizada de la economía 
caracterizando la era neo-liberal del capitalismo.

El modelo de consumo individual (vivienda, transporte) era muy energivoro. Por otra parte, la liberalización del comercio exterior llevó a más del 60 \% de las mercancías a cruzar los océanos, con todo lo que eso significa en términos de uso de energía y contaminación de los mares. Cada dia, más de 22.000 buques de más de 300 toneladas, navegan en los mares (Malen Ruiz de Elvira, 2010). Tal circulación no solamente asegura el intercambio deseable de bienes, sino que también garantiza la posibilidad de aplicar los principios del intercambio desigual con las periferias, productoras de materia prima y de bienes agrícolas. Además permite a las "ventajas comparativas" ser utilizadas de lleno. Así, los productos pueden venderse a un precio menor, a pesar de haber recorrido miles de kilómetros, porque los trabajadores son más explotados y porque las leyes de protección ecológica son inexistentes o demasiado tímidas.

Los picos del petróleo, del gas, del uranio pueden discutirse en términos de años precisos, pero de todas maneras se sabe que estos recursos no son inagotables y que las fechas no son lejanas. Países, como Estados Unidos, Inglaterra, México y varios otros han entrado en este proceso. Con el agotamiento, los precios de estos productos aumentarán inevitablemente, con todas las consecuencias sociales y politicas que esto conlleva. Por otra parte, el control internacional de las fuentes de energía fósil y otras materias estratégicas es cada vez más importante para las potencias industriales que no dudan en recurrir a la fuerza militar para asegurarlo. El mapa de las bases militares de los Estados Unidos lo indica claramente y las guerras en Irak y Afganistán lo confirman. El papel de los Estados Unidos como garante del sistema mundial es bastante claro, cuando se sabe que tienen un presupuesto militar que se acerca al $50 \%$ de todos los gastos de esta índole en el mundo. Ningún país, ni Gran Bretaña, ni Rusia, ni China, llegan a un cuarto de lo que Estados Unidos gasta. Evidentemente, no se trata solo de controlar las fuentes de energía, sino de asegurar la reproducción del conjunto del modelo.

En este contexto de futura escasez de energia, se inscribe la cuestión de los agrocombustibles. Frente a la expansión de la demanda y a la previsible disminución de los recursos energéticos fósiles, hay cierta urgencia en encontrar soluciones. Como la creación de nuevas fuentes de energía exige el desarrollo de tecnologias que todavía no están suficientemente avanzadas (como la energía solar o el hidrógeno) y que otras dan soluciones interesantes pero marginales o económicamente poco rentables (de nuevo la energía solar o la eólica), la solución de los agro-combustibles parecía interesante (François Houtart, 2009). Se habló de biocombustibles, porque la materia de base era viva y no muerta como en el caso de los combustibles fósiles, pero los movimientos sociales, en particular los campesinos, reaccionaron contra este tipo de vocabulario, en función del carácter destructor de la vida que implica la producción masiva de agro-energía (destructor de naturaleza y seres humanos). Durante un tiempo esta solución fue propuesta por organizaciones y movimientos ecologistas y bastante despreciada por los responsables de la economía. A mediados de los años 2000, la actitud de estos últimos cambió. La producción de etanol a partir de la caña de azúcar en Brasil y del maíz en Estados Unidos, comprobó que la tecnología era relativamente simple. Lo mismo sucedió con el agro-diesel a partir 
de la palma, la soja o de otras plantas que producen aceite, como la jatropha. En Brasil, el inicio de la ola productiva de etanol correspondió a la crisis petrolera de 1973, permitiendo la reducción de la importación de crudo muy costoso. Para los Estados Unidos, el problema era reducir su dependencia de las regiones exteriores, siendo varias de ellas poco confiables, lo que justificó una producción de etanol con importantes subsidios estatales, siendo el maíz menos provechoso que la caña en materia de agro-combustibles.

Muchos países empezaron a decretar la utilización de un cierto porcentaje de "energía verde" en su consumo general. La Unión Europea decidió que este consumo sería del $20 \%$ en el año 2020, con un $10 \%$ de energía líquida verde, es decir de agro-combustible. El conjunto de estos planes significaba la necesidad de dedicar millones de hectáreas de cultivo a este fin. De hecho, ni Europa, ni Estados Unidos, tienen suficientes tierras para satisfacer su demanda, dado su enorme consumo. El resultado fue que desde finales de la primera década de 2000, se reveló un interés creciente hacia los continentes del Sur, los cuales disponen de muchas tierras no cultivadas.

La producción de agro-combustibles se realiza bajo la forma de monocultivos, es decir con la utilización de grandes extensiones para un solo producto. En muchos casos, eso conlleva la supresión de grandes bosques como en el caso de Malasia o de Indonesia, donde, en menos de 20 años, el $80 \%$ de la selva original fue destruida por plantaciones de la palma y eucalipto. La biodiversidad está eliminada, con todas las consecuencias sobre la reproducción de la vida. Para producir agro-combustibles, se utiliza no solamente mucha agua, sino una gran cantidad de productos químicos como fertilizantes o pesticidas. El resultado es una contaminación intensiva de las aguas subterráneas, de los ríos, hasta del mar y un peligro real de falta de agua potable para las poblaciones. Además, los pequeños campesinos son expulsados y muchas comunidades indigenas pierden sus tierras ancestrales, lo que provoca un sinnúmero de conflictos sociales, aun violentos. Si los planes se realizan entre esta fecha y 2020, decenas de millones de hectáreas serán dedicadas al monocultivo de agro-combustibles en Asia, África y América Latina, continentes en donde se ubica la mayoría de los casi mil millones de hambrientos del planeta. Todo eso por un resultado marginal en términos de energía.

Asistimos a un doble fenómeno; por una parte la entrada del capital financiero y especulativo en el sector agro-energético y por otra parte al acaparamiento de tierras, especialmente en África. En Guinea Bissau existe un plan para convertir 500.000 hectáreas, es decir un séptimo de la superficie del país, en cultivo de jatropha, para producir agro-diesel. El capital vendría de los casinos de Macao (en donde se habla portugués como en Guinea Bissau, lo que ayuda a concretar negocios y cerrar transacciones) y el banco encargado de la operación tiene como principal accionista al Primer Ministro. Hasta ahora, la resistencia campesina y las dudas de varios ministros (incluido el Primer Ministro), han detenido el proyecto, pero no sabemos hasta cuando eso será posible ¿Decenas de proyectos similares existen en muchos otros países, como Tanzania, Togo, Benín, Camerún, Congo, Kenia, etc. 
En octubre de 2010, se firmó un acuerdo en Brasilia, entre el Presidente Lula, el Sr. Herman Van Rompuy, Presidente del Consejo de Europa y el Sr. Barroso, Presidente de la Comisión europea, para desarrollar 4 millones 800.000 hectáreas de caña de azúcar en Mozambique (también un séptimo de las tierras del país), con tecnología brasileña y financiamiento europeo, a fin de abastecer a Europa de etanol y permitir a esta última cumplir con su plan de utilización de energía "verde", sin preocuparse de los efectos en el ambiente natural y las poblaciones. El desarrollo de los agro-combustibles corresponde al olvido de las externalidades ecológicas y sociales, típico de la lógica del capitalismo. Es un cálculo a corto plazo, que no tiene en cuenta los costos que el mercado no asume, sino más bien la naturaleza, las sociedades y los individuos. Estas prácticas corresponden también a las leyes de la acumulación y a los intereses inmediatos del capital financiero. En otras palabras es un proyecto típicamente capitalista.

\section{La Crisis climática}

La crisis climática es bastante conocida y las informaciones son cada día más precisas, gracias a diversas conferencias de la ONU sobre el clima, sobre la biodiversidad, los glaciales, etc. Recordaremos solamente lo esencial de la situación. Al mismo tiempo que el modelo actual de desarrollo sigue emitiendo más gases de efecto invernadero (especialmente el C02), se destruyen los sumideros de carbono, es decir los lugares naturales de absorción de estos gases, en particular las selvas y los océanos. Además, la destrucción de muchos ecosistemas, por la utilización masiva de productos químicos, el monocultivo, la explotación de recursos naturales, como el petróleo, el gas, los minerales, provoca daños irreversibles que pueden incluso afectar el clima. El calentamiento del planeta aumenta, el aumento del nivel de los mares se acentúa. Tenemos solamente un planeta, eso significa que el modelo no es sustentable. Además, según el informe de 2006, del Dr. Nicholas Stern para el Gobierno británico, si la tendencia actual sigue, habría entre 150 y 200 millones de migrantes climáticos para la segunda mitad del siglo XXI. Investigaciones más recientes presentan cifras aún más altas (Nicholas Stern, 2006).

Debemos añadir dos aspectos que no siempre fueron subrayados. El primero es la "deuda ecológica". Desde el desarrollo del capitalismo mercantil, se organizó la explotación de las riquezas naturales del Sur, con un costo humano y ecológico enorme. Las externalidades de este saqueo fueron pagadas en su totalidad por las regiones colonizadas. La independencia política de estos países no cambió la lógica de la relación. Durante los últimos años, el acaparamiento de las tierras y la sobreexplotación minera para resolver las necesidades del Norte, se aceleraron, provocando desastres ecológicos, sin hablar de los conflictos sociales. Así la deuda ecológica debe añadirse al fenómeno de la deuda externa, pública o privada de los países del Sur. Sería justo que los consumidores de productos extraídos del Sur sean los que paguen las consecuencias de las externalidades (daños a la naturaleza e injusticias sociales). De esta manera ellos contrajeron una verdadera deuda.

El otro aspecto es el costo ecológico militar. Primero, las guerras representan un despilfarro gigantesco que afecta a la naturaleza por la destrucción ecológica de los bombardeos, la utilización de productos químicos ${ }^{3}$, la emisión de CO2; por 
otra parte, la producción del armamento significa el uso de muchas materias que agotan la riqueza natural de la tierra y sus procesos de producción emiten gases de efecto invernadero. No se gasta casi 1000 billones de dólares cada año, sin causar graves daños a los ecosistemas.

Todo esto desemboca en un panorama social donde la riqueza se concentra, incluyendo los poderes de decisión, económicos y políticos. Según el PNUD, un veinte por ciento de la población mundial, absorbe más del 80 \% de los recursos económicos del planeta. Durante las últimas décadas, muchos millones de personas accedieron a este nivel de consumo y constituyen un poder de compra muy útil para la reproducción del capital y una presa fácil para la compra de los productos derivados. Los otros son (como lo dice Susan George), "muchedumbres inútiles" (S. George, 2005). Lo cierto es que no contribuyen al aumento de un valor agregado, ni tienen poder de compra alguno -o muy poco-. Las distancias sociales, como lo reconoció el Banco Mundial, aumentan (Banco Mundial, Informe 2006). Se crea así, como resultado del múltiple desorden, una situación global de crisis del modelo de desarrollo. Algunos hablan aún de una crisis de civilización, que se manifiesta igualmente en el descontrol de la urbanización, la crisis del Estado, la extensión de la violencia para resolver los conflictos, y muchos fenómenos del mismo orden, lo que plantea evidentemente la cuestión de las soluciones para salir de una situación tan mundialmente preocupante. Diferentes opiniones se manifiestan esencialmente en tres direcciones.

\section{¿Qué soluciones?}

\section{Cambiar los actores, no el sistema}

Algunos, principalmente preocupados por la crisis financiera, proponen castigar y cambiar los actores inmediatos de la argamasa económica, "los ladrones de gallinas", como decía Michel Camdessus, el ex director del FMI. Esta posición representa la teoría del sistema capitalista (tesis neo-clásica en economía) que ve en las crisis elementos favorables, porque ellas permitan liberarse de los elementos débiles o corruptos para reanudar el proceso de acumulación sobre basas sanas. Se cambian los actores, para no cambia el sistema.

\section{Establecer regulaciones}

Una segunda visión consiste en proponer regulaciones. Se reconoce que el mercado no se regula por sí mismo y que se necesitan órganos nacionales e internacionales para cumplir con esta tarea. El Estado y los Organismos internacionales específicos deben intervenir. El mismo Michel Camdessus en una conferencia a los empresarios católicos de Francia, hablaba de las tres manos: la invisible del mercado, la reguladora del Estado y la mano de la caridad para las víctimas que escapan a los dos otros procesos. Unos de los principales teóricos de esta posición fue John Maynard Keynes, el economista inglés. Por eso se utiliza la palabra "neo-keynesianismo" en el contexto actual. Regular el sistema significa salvarlo y en este caso, redefinir el papel de las instituciones públicas (el Estado y las Instituciones internacionales) tan necesarias para la reproducción del capital y que el neo-liberalismo de los años 70 parecía haber 
olvidado (Ernesto Molina Molina, 2010, 25).

Sin embargo, las propuestas concretas son diversas. E1 G8, por ejemplo, propuso establecer ciertas regulaciones del sistema económico mundial, pero ligeras y provisionales. Al contrario, la Comisión de las Naciones Unidas sobre la Crisis Financiera y Monetaria, presentó una serie de regulaciones mucho más avanzadas (Joseph Stiglitz, 2010). Así, se propuso la creación de un Consejo Global de Coordinación Económica, a la par del Consejo de Seguridad y también un Panel Internacional de Expertos, con el fin de monitorear de manera permanente la situación económica mundial. Otras recomendaciones trataban de la abolición de los paraísos fiscales y del secreto bancario, o también de de mayores exigencias de reservas bancarias y un control más estricto de las agencias de notación. Una reforma profunda de las instituciones de Bretton Woods estaba incluida y la posibilidad de establecer monedas regionales en vez de tener como sola moneda de referencia el dólar de los Estados Unidos. Según el informe, todo eso tenía como objetivo la promoción de un "nuevo y robusto crecimiento". Eran medidas bastante fuertes contra el ambiente neo-liberal, pero la Conferencia de las Naciones Unidas que tuvo lugar en junio 2009 sobre el tema, adoptó a penas algunas prudentes medidas, rápidamente interpretadas de manera minimalista por las grandes potencias occidentales.

Las regulaciones propuestas por la Comisión Stiglitz para reconstruir el sistema financiero y monetario, a pesar de algunas referencias a los otros aspectos de la crisis, como el clima, la energía, la alimentación, y a pesar de la utilización de la palabra sustentable para calificar el crecimiento a ser recuperado, no se preguntó de manera suficientemente profunda sobre los fines: ¿reparar el sistema económico, para qué? ¿Para desarrollar como antes, un modelo destructor de la naturaleza y socialmente desequilibrado? Es muy probable que las propuestas de la Comisión para reformar el sistema monetario y financiero sean eficaces para salir de la crisis financiera, y mucho más eficaces que lo que se ha hecho hasta ahora, pero ¿Es eso suficiente para enfrentar los desafios globales contemporáneos? La solución se queda en el capitalismo, un sistema históricamente agotado, aún si tiene todavía muchos medios de adaptación. La transición hacia un sistema construido sobre otras bases requiere evidentemente regulaciones, pero no de cualquier tipo; la idea es llegar a otra situación y no adaptar el sistema a nuevas circunstancias.

\section{Buscar alternativas al modelo prevalente}

Es por eso que una tercera posición se vuelve necesaria: poner en tela de juicio el modelo mismo de desarrollo. La multiplicidad de las crisis que se agudizaron en los últimos tiempos, son el resultado de la misma lógica de fondo: (1) una concepción del desarrollo ignorando las "externalidades" (es decir los daños naturales y sociales); (2) basada sobre la idea de un planeta inagotable; (3) dando al valor de cambio el predominio sobre el valor de uso y (4) identificando la economía con la tasa de ganancia y la acumulación del capital, creando enormes desigualdades. Este modelo que resultó en un desarrollo espectacular de la riqueza mundial, ha llegando al fin de su función histórica, debido a su carácter destructor de la naturaleza y a la desigualdad social que ha provocado. No puede reproducirse, o dicho en palabras 
contemporáneas, ya no es sostenible. "La racionalidad económica del capitalismo escribe Wim Dierckxsens-, no solo tiende a negar la vida de amplias mayorias de la población mundial sino que destruye la vida natural que nos rodea" (2011).

Jorge Beinstein, el economista argentino, afirma que hubo en las últimas cuatro décadas una decadencia del capitalismo a escala mundial (una caída del sector productivo) solamente velada durante un tiempo por el desarrollo artificial del sector financiero y por la importancia de los gastos militares (Jorge Beinstein, 2009, 13). Por eso, está claro que no se puede hablar solamente de regulaciones, sino que se debe pensar en alternativas. Estas últimas no son reflexiones puramente teóricas, sino que deben desembocar necesariamente en politicas concretas a largo, pero también a corto y mediano plazo.

Hablar de alternativas al modelo económico capitalista, hoy prevalente por su globalización, y sus dimensiones sociales, políticas, culturales y de género, significa revisar el paradigma mismo (la orientación de base) del vivir colectivo de la humanidad en el planeta, tal como fue definido por la lógica del capitalismo, que ahora se ha globalizado. El vivir colectivo se compone de cuatro elementos a los que podemos llamar sus fundamentos, porque son parte de las exigencias de la vida de cada sociedad, desde la más antigua, hasta la más contemporánea. Estos son (1) la relación con la naturaleza, (2) la producción de la base material de la vida, física, cultural y espiritual, (3) la organización colectiva social y política y (4) la lectura de lo real y la auto-implicación de los actores en su construcción, es decir la cultura. Cada sociedad tiene que realizar esta tarea.

El paradigma actual que orienta la construcción del mundo contemporáneo se resume en una palabra: "modernidad". Es el fruto de la trasformación profunda de la sociedad y la cultura europeas (definió sus propios paradigmas), que significó un avance que no se puede negar (Bolivar Echeverria, 2001). Sin embargo, la modernidad no es una abstracción social, nacida del azar o de la nada. Se trata de un modo de vida colectivo en la tierra, con sus bases materiales y sociales y su producción de ideas, bien establecido en la historia y siguiendo un proceso dialéctico de contradicciones internas. La emancipación de la persona, los derechos humanos, la idea de democracia, el progreso de la ciencia y de sus aplicaciones técnicas, son algunos de sus frutos. Sin embargo, la hegemonía del mercado capitalista y sus leyes, redujo la mayor parte de estos avances a privilegios de clase y relaciones coloniales, brutalmente mantenidas durante cinco siglos. Numerosas luchas sociales incluyeron a una parte de los grupos subalternos en las ventajas de la modernidad, pero no trasformaron el paradigma. Ahora bien, este paradigma, con sus contradicciones, ha puesto en peligro los cuatro elementos fundamentales de la vida colectiva de la humanidad en la tierra. Con la distancia entre lo humano y lo natural, el paradigma de la modernidad desembocó en la sobre-explotación de la naturaleza, es decir en la devastación de la fuente de la vida (la madre-tierra). Este paradigma ha dado nacimiento a la economía de mercado capitalista que invadió con su lógica todos los sectores de la vida. En lo político, el Estado jacobino nace de esta visión. En la cultura, la exacerbación del individualismo se estableció como un imperativo ético, junto con la concepción del progreso indefinido de la humanidad, viviendo en un planeta inagotable y capaz de resolver las contradicciones a través 
del uso de la ciencia y la tecnología, orientó el modelo de desarrollo, hasta las sociedades socialistas del siglo XX.

La hegemonía global de este proyecto se manifestó muy temprano, en la destrucción, la absorción o la sumisión de todos los modos de producción pre-capitalistas, en las varias empresas coloniales, en el establecimiento del intercambio desigual entre los centros y las periferias y finalmente en lo que se llamó recientemente la "globalización", que finalmente identificó los conceptos de crecimiento y de occidentalización, es decir la universalización de la últimas formas de hegemonía del capital.

Una reacción contra este modelo se expresó en el posmodernismo. Sin embargo, este pensamiento, que se desarrolló desde la segunda mitad del siglo XX, conllevó también una crítica de la modernidad particularmente ambigua, que se limitaba generalmente a la esfera cultural y política (M.Maffesoli, 1990). La visión de la historia como construida en lo inmediato por actores individuales, el rechazo a reconocer la existencia de estructuras, la negación de la realidad de los sistemas, definidos exclusivamente por sus características verticales, la voluntad explícita de no aceptar teorias en ciencias humanas, han hecho de esta corriente un hijo ilegitimo de la modernidad misma, conduciendo a la despolitización. El posmodernismo se ha convertido en una ideología muy funcional para el neo-liberalismo. En un momento en el que el capitalismo había edificado las nuevas bases materiales de su existencia como "sistema-mundo", según la expresión de Immanuel Wallerstein, negar la existencia misma de sistemas era muy útil para los promotores del "Consenso de Washington". Es importante criticar la modernidad, pero con un enfoque histórico y dialéctico (actores en interacción, con varios grados de poder) y tratando de recuperar el carácter emancipador que significó en una fase de la historia humana. No se puede identificar a la modernidad con el capitalismo, pero tampoco se puede hablar de modernidad sin incluir al capitalismo.

Por esta razón, reconstruir un cuadro teórico coherente es un imperativo, aprovechando el aporte de las diversas corrientes del pensamiento humano, tanto en el orden filosófico como en las ciencias, físicas, biológicas y sociales. No partimos en este dominio de un vacío, sin embargo, las nuevas circunstancias exigen una renovación de las perspectivas y una redefinición de los paradigmas de la vida colectiva de la humanidad en el planeta. De la misma manera, toda acción social y política tiene que inscribirse dentro de este cuadro general para contribuir a la elaboración de alternativas. Es importante definir el lugar de cada una de ellas en el conjunto, dando así una coherencia a lo que podría parecer una serie de acciones separadas sin mucha relación entre ellas (el empirismo). Esto vale también para las politicas internacionales.

Como ya lo hemos dicho, los fundamentos de la vida colectiva de la humanidad en el planeta son cuatro: la relación con la naturaleza; la producción de la base de la vida (economía); la organización colectiva, social y política y la lectura y la expresión simbólica de lo real. Es al cumplimiento de un nuevo paradigma en estos cuatro elementos, en (las) circunstancias dadas, a lo que llamamos la realización del Bien Común de la Humanidad, (como se ha dicho antes,) es decir la posibilidad de reproducción de la vida. Se trata de un objetivo a perseguir de manera permanente 
y que no se define de una vez por todas, porque las circunstancias históricas cambian el contexto. La crisis actual requiere sin embargo de una reflexión radical (que va a la raíz) (István Mészarós, 2008, 86) y que significa una reorientación profunda frente al paradigma originario del capitalismo. El concepto de Bien Común de la Humanidad ha tenido muchas expresiones diferentes según las tradiciones de pensamiento y las experiencias colectivas de los pueblos, por ejemplo en las filosofias y religiones orientales y de los pueblos indígenas de las Américas (el Sumak Kwasay o el buen vivir), como también en la tradición marxista del sistema de necesidades y capacidades universales (Antonio Salamanca Serrano, 2011, 46 y Solange Mercier-Jesa, 1982)

\section{Un nuevo paradigma y sus aplicaciones}

En resumen, podemos decir que el paradigma de desarrollo humano expresado en la modernidad es un progreso material y científico indefinido, en un planeta inagotable, a disposición exclusiva de los seres humanos, para aprovechar siempre con más libertad, de bienes y servicios. Este modo de vida está sustentado en la eficacia de una economía de competencia (elemento particularmente masculino) y está llegando a su agotamiento, por el peso de sus contradicciones sociales y ecológicas. De ahí la necesidad de un cambio radical para asegurar a largo plazo la continuidad de la vida de la tierra y de la humanidad. No se trata de retornar a las cavernas, sino de redefinir los fundamentos de la vida colectiva de la humanidad en la tierra.

El nuevo paradigma plantea como opción fundamental, una dinámica social equilibrada entre personas, géneros y grupos sociales, en armonía con la naturaleza, para promover la vida y asegurar su reproducción. Se trata de vivir bien, de cumplir con el Bien Común de la Humanidad, lo que implica, como primer paso, el respeto de la integridad de la naturaleza, como fuente de vida (la madre-tierra).

Su construcción y sus aplicaciones en los fundamentos de la vida colectiva en el planeta, son un proceso. No se trata solamente de un ejercicio académico, sino de una elaboración social, donde el pensamiento tiene un lugar esencial, pero también la experiencia concreta, en particular las luchas sociales, que corresponden cada una a una falla de cumplimiento del Bien Común de la Humanidad y que buscan soluciones. Dado que la globalización destructiva del capitalismo ha hegemonizado las economías, las sociedades y las culturas del mundo entero, pero no las ha eliminado completamente, la tarea es de todos, hombres y mujeres, según sus características y sus experiencias históricas. Nadie puede ser excluido de este esfuerzo común de reelaboración de las condiciones de la vida. Sin embargo, este paradigma no es tan nuevo. En las sociedades pre-capitalistas del mundo entero hemos conocido referencias de este tipo, es decir una visión completa (holística) del destino humano sobre la tierra. Muchas veces ella se expreso en términos religiosos, tanto en las tradiciones de base filosófica (taoísmo, confucianismo, hinduismo, budismo, judaísmo, cristianismo, islam) como en las religiones tradicionales. Se trata de redescubrir, en términos contemporáneos, para el mundo de hoy, las perspectivas adecuadas y de traducirlas a algo concreto. 


\section{Redefinir las relaciones con la naturaleza: de la explotación al respeto como fuente de vida}

La civilización moderna con su control importante de la naturaleza, su alta grado de urbanización, ha hecho olvidar a los seres humanos que, en última instancia, ellos dependen totalmente de la naturaleza para vivir. Los cambios climáticos les recuerdan, a veces con gran brutalidad, esta realidad. Entonces, se trata de definir la relación, no como la explotación de la tierra, en tanto que fuente de recursos naturales capaces de ser reducidos al estatuto de mercancía, sino como la fuente de toda vida, en una actitud de respeto a su capacidad de regeneración física y biológica. Eso evidentemente significa un cambio filosófico radical. Se trata de criticar el carácter puramente utilitario de la relación, que en el capitalismo llega a considerar los daños ecológicos como colaterales (eventualmente a reducirlos en la medida de lo posible), pero inevitables, o aún peor, como "externalidades", porque no entran en los cálculos del mercado y por consiguiente, en la acumulación del capital.

Algunos autores van más lejos y ponen en tela de juicio el enfoque antropocéntrico de tales perspectivas (E. Gudymas, 2009, 68), proponiendo nuevos conceptos como el derecho de la naturaleza, lo que el teólogo brasileño Leonardo Boff (2000) ha defendido en varios de sus escritos. Es sobre esta base que el Presidente de la Asamblea general de las Naciones Unidas, Miguel D'Escoto propuso en 2009, en su discurso de despedida, una Declaración Universal de los Derechos de la Madre Tierra y de la Humanidad. Un dia de la Madre Tierra fue aprobado por esta misma Asamblea por unanimidad, por los 192 países representados. Se recordaba con razón, que el ser humano es parte de la naturaleza y que no se trata de establecer una dicotomía entre los dos, sino una simbiosis. Varios defensores de esta posición estiman que solamente una actitud antropocentrista puede considerar el ser humano como el centro del mundo, sin tener en cuenta a los otros seres vivientes y hasta al planeta mismo, lo que provoca los efectos ecológicos negativos que empezamos a conocer, de manera dramática.

Sin embargo, lo que llamamos el Bien común de la Tierra solamente puede ser abordado por la mediación del género humano. En efecto, es solamente a través suyo que se plantea el problema de la posibilidad de que la Tierra se regenere o no, frente a la actividad humana predatoria y destructiva. Es por eso que el Bien Común de la Humanidad pasa por la supervivencia de la naturaleza, es decir (de) la biodiversidad. Si se habla de los "derechos de la naturaleza" (Eduardo Gudynas, 2009) es en un sentido derivado o secundario, porque es solamente el género humano el que puede expresarlo en estos términos, es decir infringirlos o respetarlos. Ni la tierra, ni los animales, pueden reivindicar el respeto de sus derechos. Son los seres humanos los responsables de la destrucción de los ecosistemas. En este sentido se puede utilizar, según el jurista Antonio Salamanca, las categorias de "derecho titular o de derecho vicario, que la comunidad humana ejerce en nombre de los "nocapaces" (animales, niños no-nacidos, incapacitados) quienes para la reproducción de su vida necesitan la mediación humana. Esta posición no es antropocentrista, sino "antropo-responsabilizante". De esta manera, en un proceso de ampliación del sujeto jurídico, se puede hablar de Justicia climática, sin pasar necesariamente por una personalización de la tierra y sus elementos. Al mismo tiempo, no se puede 
ignorar que existe un vínculo entre la relación que los seres humanos tienen con la naturaleza y las relaciones de clase. No todas las clases sociales se comportan de la misma manera frente a la tierra. Se trata de una relación de poder, puesta en práctica por la lógica del capitalismo.

De todas maneras, el principio es la posibilidad de que planeta sea sustentable, es decir conserve la integridad de su biodiversidad y pueda renovarse frente a las actividades humanas. El ser humano puede también embellecer la naturaleza, utilizando sus riquezas vegetales para crear nuevos paisajes o jardines, utilizando sus elementos para producir belleza. La Tierra es también generosa y puede contribuir, aún con elementos no renovables, a la producción y a la reproducción de la vida. Sin embargo, eso es totalmente diferente de la explotación para producir una tasa de ganancia.

En las grandes tradiciones filosóficas del Oriente, la unión profunda entre el ser humano y la naturaleza es una característica del pensamiento. El respeto a toda vida, que se encuentra en el hinduismo o en el budismo traduce esta convicción, lo mismo que la creencia en la reencarnación como expresión de la unidad de la vida y de su continuidad. El hombre creado a partir del barro (la tierra), de la tradición judeo-cristiana y retomada por el islam, expresan la misma idea. La Biblia presenta al hombre como cuidador de la naturaleza (Gen. 1, 26-28). Aún si se afirma que ella está a su servicio, eso excluye evidentemente su destrucción. En muchos mitos de la creación se puede encontrar concepciones similares en varias culturas de África y de las Américas.

En los pueblos indígenas del continente americano, el concepto de la Madre Tierra (Pacha Mama) es central. Fuente de la vida, la Pacha Mama está personalizada y su representación incluye características antropomórficas, los elementos de la naturaleza también viven con su personalidad y son objeto de ritos shamánicos. En la Cumbre sobre el Clima que tuvo lugar en Cochabamba en 2010, varios textos (el documento preparatorio y varias intervenciones de grupos o personas) superaron el carácter metafórico de la expresión Madre Tierra, para atribuir a esta última las características de una persona viviente, capaz de escuchar, de reaccionar, de ser amada, y por estas razones de ser un sujeto de derechos. La declaración final pedía la revalorización de la sabiduría y de los saberes ancestrales y de "reconocer a la Madre Tierra como un ente vivo, con el cual tenemos una relación indivisible, interdependiente, complementaria y espiritual". Fue una reafirmación fuerte del vínculo entre la naturaleza y la humanidad, dentro de la cosmovisión de los pueblos indigenas, que por otra parte subraya el carácter maternal (femenino) de la relación.

Se debe reconocer, al mismo tiempo, que frente a la lógica del capitalismo, al desarrollo de la urbanización y a la atracción del consumo irracional, tanto las grandes filosofias orientales, como las tradiciones de los pueblos originales no resisten, se transforman rápidamente o aún desaparecen del panorama cultural, como es el caso en los "Tigres" asiáticos, en China y Vietnam y también entre los pueblos indígenas del continente americano y los pueblos africanos. El neoliberalismo acentuó este fenómeno en el mundo entero. Participar de los valores de la cultura dominante ha sido una aspiración individual y colectiva de muchos. 
Lo que pasó con las clases subalternas europeas y con el cristianismo -el primer sistema religioso a ser confrontado con el capitalismo-, se repite en otros lugares: la contaminación ideológica es un hecho real.

Sin embargo, hoy en día se reutilizan conceptos tradicionales como instrumentos de memoria histórica, de reconstrucción cultural y de afirmación de identidad, lo que puede ser muy útil a la crítica de la lógica del capitalismo. Hay un cierto orgullo en poder referirse a culturas históricas y en emplear sus conceptos para contribuir a un proceso de reconstrucción social. Sin embargo, el peligro de caer en un fundamentalismo paralizante, más orientado al pasado que al presente, no está totalmente ausente.

Las referencias a la Pacha Mama (Tierra Madre) o al Sumak Kawsay (Buen Vivir), de los pueblos Kichwas o Suma Qamaña (Convivir Bien) de los pueblos Aymara. (Xavier Albó, $2010,54-55)$ pertenecen a estas categorías. Son conceptos fundadores de los pueblos indigenas, significando en sus condiciones históricas concretas, cosmovisiones y prácticas de respecto a la naturaleza y de vida colectiva compartida. Pueden inspirar el pensamiento y la organización social contemporánea y devolver su fuerza al símbolo. Sin embargo, el éxito depende de las adaptaciones necesarias, "de tal forma, como lo escribe Diana Quirola Suárez, que la transformación tendrá la oportunidad de combinar lo mejor del conocimiento ancestral y moderno, con saberes y tecnologias sincronizados con el funcionamiento de la naturaleza" $(2009,107)$.

No se trata evidentemente, de cuestionar la necesaria armonía entre la naturaleza y el género humano, ni de avalar el concepto capitalista de explotación de la naturaleza en función de un desarrollo concebido como simple crecimiento material sin fin. No se trata tampoco de negar la necesidad de revisar la filosofia de esta relación que ignora las otras especies vivientes y la capacidad de reproducción del equilibrio de la naturaleza. No se puede finalmente despreciar ni marginalizar a las culturas que pueden hoy aportar a la humanidad una crítica saludable, tanto de la relación de explotación, trasmitida por la lógica del capitalismo, como del individualismo exacerbado del modelo de consumo y de los otros comportamientos que caracterizan esta última. Sin embargo, se debe reconocer que existen culturas diferentes. Querer expresar el cambio necesario únicamente en términos de un pensamiento simbólico, que identifica el símbolo con la realidad, significa chocar con culturas caracterizadas por un pensamiento analítico que sitúa la causalidad de los fenómenos en sus campos respectivos, físico o social.

Los dos tipos de culturas coexisten hoy. La primera con una riqueza de expresión recordando la fuerza del símbolo y la importancia del campo de los ideales, particularmente en el dominio de las relaciones con la naturaleza, implicando de verdad parámetros prácticos que se pueden perfectamente traducir en saberes, comportamientos y politicas, pero con una cosmovisión difícilmente asimilable por una cultura urbana en cualquier parte del mundo. La segunda, que ciertamente ha reducido la cultura a una racionalidad instrumental o a una pura "superestructura" (la cereza sobre el pastel, como dice el antropólogo francés Maurice Godelier), reforzando así la lógica del capitalismo y contribuyendo a su reproducción, también permitió un desarrollo importante del conocimiento, útil para solucionar problemas 
prácticos y políticos. No sería sabio, en una lucha contra el capitalismo globalizado que conduce la humanidad y el planeta al desastre, expresarse en un solo lenguaje cultural. Al contrario, es el momento de aplicar el principio de la interculturalidad en todas sus dimensiones.

Hemos hecho alusión previamente al aporte de Carlos Marx. Para él, el capitalismo provocó una separación artificial y mecánica entre la naturaleza y el ser humano. La ruptura de equilibrio en el metabolismo, es decir el intercambio material entre la tierra y la satisfacción de las necesidades de los seres humanos, tal como ha sido definido por el proceso de acumulación del capital, desembocó en esquemas irracionales, despilfarros y destrucciones (El Capital, Vol. 1, 637-38, citado por Gian Delgado, 2011). Por eso se deben reducir los flujos energético-naturales, de manera socialmente justa, para incrementar la calidad de la vida. Según Marx, solamente el socialismo podrá restablecer el equilibrio del metabolismo y poner fin a la devastación de la naturaleza.

La afirmación de una nueva concepción de las relaciones con la naturaleza, conlleva muchas consecuencias prácticas. Citaremos algunas de ellas a título de ejemplos, reagrupándolas en tres partes: las prohibiciones o limitaciones, las iniciativas positivas y lo que eso implica para una politica de relaciones exteriores.

- En la primera perspectiva, la aplicación consiste en no aceptar la propiedad privada de lo que se llama "los recursos naturales", es decir los minerales, las energias fósiles, las selvas. Se trata de un patrimonio común de la humanidad que no puede ser apropiado por individuos y corporaciones, siguiendo la lógica de la economía de mercado capitalista, es decir en función de intereses privados ignorando las externalidades y orientados por la maximización de la ganancia. Un primer paso en una transición consiste en la recuperación de la soberania de los Estados sobre sus riquezas naturales, pero aún eso no asegura el resultado esperado de una buena relación con la naturaleza. Empresas nacionales actúan a menudo dentro de la misma lógica y en este sentido, la soberanía estatal tendría que integrar la filosofia del respeto en vez de la explotación. La internacionalización de este sector sería el paso ulterior, condicionado sin embargo por una real democratización de las instituciones de esta índole (las Naciones Unidas y sus órganos), que en muchos casos están bajo la influencia de los poderes hegemónicos políticos y económicos. Dentro de esta misma perspectiva la exigencia de introducir los costos ecológicos de toda actividad humana en los cálculos económicos permitiría reducir estos últimos y contrariar la racionalidad instrumental excluyendo las externalidades, que fue una de las bases del carácter destructivo del capitalismo.

Otro aspecto es el rechazo a la mercantilización de los elementos necesarios para la reproducción de la vida, como el agua y las semillas. Son bienes comunes que deben salir de la lógica de la mercancía y entrar en una perspectiva de gestión común según varias modalidades, que no implican necesariamente la estatización, sino el control colectivo. De manera todavía más concreta, este principio implicaría poner fin a los monocultivos que preparan las regiones inhabitables del futuro, en particular en materias de alimentos para el ganado y de agro-combustibles. Una tasa sobre los kilómetros recorridos por productos industriales o agrícolas 
permitiría reducir tanto el uso de energía como la contaminación de los mares. Otras medidas similares podrían ser también pensadas.

2- De manera positiva, las reservas de biodiversidad tendrian que ser extendidas a más territorios. La promoción de la agricultura orgánica haría parte de este proyecto, como el mejoramiento de la agricultura campesina, más eficaz a largo plazo que la agricultura productivista capitalista (Oliver De Schutter, 2011). Exigir una prolongación de la "esperanza de vida" de todos los productos industriales permitiria un ahorro de materias primas, de energía y una disminución de la producción de gases a efecto invernadero (Wim Dierckxsens, 2011).

3- Finalmente en el orden de la politica internacional, la lucha contra las orientaciones de base de las instituciones financieras que contradicen el principio del respeto a la naturaleza comporta un gran número de capítulos. Se trata del Banco Mundial, del Fondo Monetario Internacional, de los Bancos regionales y también de la regulación de la Banca privada, tan poderosa en este tiempo de financiarización de la economía mundial. Las orientaciones de la OMC a favor de la liberalización del comercio mundial, también tienen sus vertientes ecológicas, porque ella se realiza en mayor parte ignorando las externalidades. Los países miembros de esta organización internacional tienen una gran responsabilidad en este sector y las alianzas entre naciones ecológicamente conscientes podrían influir en las decisiones.

La promoción de convenciones internacionales es otro sector de gran importancia. Se puede citar a título de ejemplos, las convenciones sobre el clima (Conferencia de Cancún), la biodiversidad (Conferencias de Bonn y Nagoya), sobre la protección de las aguas (ríos y mares), sobre la pesca, sobre los deshechos (en particular nucleares) y varias otras. Un alto grado de sensibilidad al nuevo paradigma sería primordial en la eficacia internacional de los Estados progresistas y podría figurar en la agenda de su política exterior.

La redefinición del Bien Común de la Humanidad en función de la relación con la naturaleza es una tarea esencial frente a los daños ecológicos y a sus consecuencias en la capacidad regeneradora del planeta así como en el equilibrio climático. Eso es un hecho nuevo en la consciencia colectiva, pero está lejos de haber ya sido compartido por todos los grupos humanos. Las sociedades socialistas no integraron realmente esta dimensión en sus perspectivas y eso se comprueba todavía hoy en el espectacular desarrollo económico de un país como China que se realiza sin dar mucha atención, por lo menos inmediata, a las externalidades. Un socialismo del siglo XXI tendrá que integrar este elemento como central. 


\section{Reorientar la producción de la base de la vida, privilegiando el valor de uso sobre el valor de cambio}

El cambio de paradigma en su relación con la economía consiste en privilegiar el valor de uso en vez del valor de cambio, como lo hace el capitalismo. Se habla de valor de uso cuando un bien o un servicio adquiere una utilidad para satisfacer las necesidades de la vida de uno. Los bienes adquieren un valor de cambio cuando son objeto de una transacción. La característica de una economía mercantil es privilegiar el valor de cambio. Para el capitalismo, la forma más desarrollada de la producción mercantil, este último es el único "valor". Un bien o un servicio que no se convierte en mercancía, no tiene valor, porque no contribuye a la acumulación del capital, fin y motor de la economía (M. Godelier, 1982). En esta perspectiva, el valor de uso es secundario y, como lo escribe István Mészarós, "puede adquirir el derecho a la existencia si se amolda a los imperativos del valor de cambio" (2008, 49). Incluso se puede producir bienes sin ninguna utilidad a condición de que sean pagados (la explosión de los gastos militares, por ejemplo, o los elefantes blancos de la cooperación internacional). Se crean necesidades artificiales (por la publicidad) (Wim Dierckxsens, 2011) o también se amplian los servicios financieros en burbujas especulativas. Al contrario, dar mayor importancia al valor de uso hace del mercado un servidor de las necesidades humanas.

De verdad, el concepto de necesidades es relativo. Cambia con las circunstancias históricas y el desarrollo de las fuerzas productivas. El principio es que todos los seres humanos tienen el derecho a satisfacer sus necesidades vitales. Es lo que la declaración Universal de los Derechos Humanos afirma de manera enfática. Sin embargo, eso no se realiza en abstracto, sino en circunstancias económicas, sociales y politicas bien determinadas. La relatividad no puede significar desigualdades injustas, los unos teniendo más necesidades que otros en función de su situación de clase, de género o de etnicidad. La satisfacción de las necesidades básicas tiene que ser definida por la comunidad a diversos niveles, dentro de un proceso democrático y por organismos competentes (parlamentos nacionales e internacionales, asambleas representativas); es lo que se podría llamar el establecimiento de una "economía moral", es decir sometida a imperativos éticos que contradicen el predominio del valor de cambio en tanto fuente de acumulación del capital y fin último de la economía.

Esto no es posible sin cuestionar la propiedad privada de los principales medios de producción, lo que precisamente permite el ejercicio de un poder de decisión a favor de los detentores de los bienes de capital y una subordinación del trabajo al capital, real (directamente a través del salario) o formal (indirectamente por medio de otros mecanismos, como politicas monetarias, déficits y deudas de los Estados, especulación en los precios de los alimentos y de la energía, privatizaciones de los servicios públicos, etc. $)^{4}$. El control exclusivo del capital sobre el proceso de producción también origina la degradación del trabajo mismo (Jorge Benstein, 2009, 21) y la no valoración del trabajo de las mujeres, esencial, sin embargo, para la reproducción de la vida en todas sus dimensiones. Es evidente que la estatización completa como contrapeso al mercado total no es una solución satisfactoria, como las experiencias socialistas del pasado lo comprobaron. Existe una multitud de formas de control colectivo, desde las cooperativas hasta las asociaciones de ciudadanos. 
De ahí una definición totalmente diferente de la economía. No se trata más de producir un valor agregado en beneficio de los propietarios de los bienes de producción o del capital financiero, sino de la actividad colectiva destinada a asegurar las bases de la vida física, cultural y espiritual de todos los seres humanos en el planeta. No se puede aceptar una economía mundial y nacional basada en la explotación del trabajo para maximizar la tasa de ganancia, ni una producción de bienes y servicios destinados al $20 \%$ de la población mundial que tiene un poder de compra bastante elevado, dejando a los demás excluidos de la repartición, porque no producen un valor agregado y no disponen de ingresos suficientes. Redefinir la economía significa (así) un cambio fundamental. Evidentemente privilegiar el valor de uso, lo que implica un desarrollo de las fuerzas productivas, debe realizarse de acuerdo con el primer fundamento, el respeto a la naturaleza y también con los dos otros que abordaremos más adelante, la democracia generalizada y la interculturalidad. No excluye los intercambios, necesarios también para satisfacer nuevos valores de uso, pero a condición de no crear desequilibrios en el acceso (a) local a valores de uso y de incluir las externalidades en el proceso.

Crecimiento y desarrollo no son conceptos equivalentes. Es lo que los economistas neo-clásicos y aún los neo-keynesianos parecen olvidar. Como lo dice Jean-Philippe Peemans, profesor de la Universidad Católica de Lovaina, se impuso "la lógica de la acumulación como la única lógica del desarrollo" (Jean-Philippe Peemans, 2010, 33). Una nueva reflexión ha tenido lugar con varias formas de expresión. Una de ella fue la de retomar el concepto de los pueblos indigenas de América Latina "el buen vivir" (Sumak kawsay) noción mucho más amplia y que implica no solamente lo contrario de un crecimiento como un fin en sí mismo, sino también la armonía con la naturaleza (Diana Quiroga, 2009, 105). Ya en los años sesenta, el Club de Roma había propuesto el crecimiento cero, como solución, a lo que ya se percibía como una vía no sostenible. En la Unión Soviética de los años cincuenta, Wolfgan Harsch publicó un libro muy original, titulado "Comunismo sin Crecimiento". La idea fue retomada de manera todavía más radical por Serge Latouche, en Francia, quien lanzó, en los noventa, el concepto de Decrecimiento, lo que inspiró a varios movimientos, principalmente en las clases medias de Europa, para reducir el consumo y respetar el entorno natural. Si bien el contenido es positivo y es importante denunciar el mito pretendido de que el crecimiento resolverá todos los problemas (Serge Latouche, 2010), la noción es bastante eurocéntrica y limitada a las clases del consumo.

Parece bastante indecente predicar el decrecimiento a poblaciones africanas o aún a los empobrecidos de las sociedades industrializadas. Un concepto como el del "Buen vivir" tiene una connotación positiva y más amplia. En Buthan, bajo la influencia del budismo, es la noción de felicidad la que fue adoptada oficialmente como meta política y social. Estos casos son tal vez pequeñas islas dentro del océano del mercado mundial, pero anuncian el desarrollo de una visión crítica del modelo contemporáneo, con una perspectiva netamente holística.

Privilegiar el valor de uso sobre el valor de cambio significa también redescubrir el territorio. La globalización hizo olvidar la proximidad para favorecer los intercambios globales, ignorando las externalidades y dando prioridad al capital financiero, el 
más globalizado de los elementos de la economía por su carácter virtual. El territorio como espacio de actividad económica, pero también de responsabilidad política y de intercambio cultural es el lugar de otra racionalidad. No se trata de reducirlo a una dimensión menor, sino de reflexionar en términos de multi-dimensionalidad, donde cada elemento, desde la unidad local hasta el mundo, tiene su función, sin hundir la una en la otra.

De alli los conceptos de soberanía alimentaria o de soberanía energética, que significan que los intercambios están sometidos a un principio superior, la satisfacción de las necesidades a la dimensión del territorio (Jean-Philippe Peemans, 2010). En la perspectiva del capitalismo, la ley del valor impone la prioridad de la mercantilización y por eso se privilegia, por ejemplo, los cultivos de exportación a la producción de alimentos para el consumo local. El concepto de seguridad alimentaria no basta, porque puede estar asegurado por intercambios basados en la destrucción de las economias locales, (de) la sobre-especialización de ciertos territorios y la globalización del transporte, gran consumidor de energía y contaminador del entorno.

En la misma línea la regionalización de las economias en todo el mundo es un paso transicional favorable, para desvincularse de un centro capitalista que transforma al resto del mundo en periferias (aún emergentes). Esto vale tanto para los intercambios, como para el sistema monetario, redibujando así un modelo globalizador.

Esto nos lleva a las medidas concretas, que son numerosas y de las cuales daremos solamente algunos ejemplos. Desde un punto de vista negativo, no se puede aceptar la prioridad del capital financiero y por eso se debe abolir los paraísos fiscales en todas sus modalidades, tanto como el secreto bancario, dos instrumentos poderosos de la lucha de clases. También establecer una tasa a los flujos financieros internacionales (tasa Tobin) podría reducir el poder del capital financiero. Las "deudas odiosas" deben ser denunciadas después de auditorías, como se hizo en el Ecuador. No se puede admitir la especulación sobre los alimentos y la energía. Una tasa a los kilómetros recorridos por los bienes industriales o agrícolas permitiría reducir los gastos ecológicos de transporte y el abuso de las "ventajas comparativas". Alargar la "esperanza de vida" de los productos industrializados permitiría un gran ahorro de materias primas y de energía y disminuiria la ganancia artificial del capital generada solamente por la rapidez de su rotación (Wim Dierckxsens, 2011).

Desde un punto de vista positivo, se puede dar muchos ejemplos también. La economía social se construye sobre otras bases lógicas que las del capitalismo. Es cierto que es todavía marginal frente a la inmensa concentración del capital oligopólico, pero es posible incentivar varias de sus formas. Lo mismo vale para las cooperativas y el crédito popular. Deben ser protegidas de la destrucción, o de su absorción por el el sistema dominante. Por su parte, las iniciativas económicas regionales son medios favorables a una trasformación de la lógica económica a condición de no ser simplemente una adaptación del sistema a nuevas técnicas de producción y así servir de instrumento de integración de las economías nacionales a un conjunto capitalista de nivel superior. La restauración de los bienes comunes privatizados por el neo-liberalismo es una vía fundamental en muchos dominios: 
servicios públicos como el agua, la energía, le trasporte, las comunicaciones, la salud, la educación, la cultura, todo lo que ahora entra en el "sistema de necesidades/ capacidades"). Eso no significa necesariamente la estatización (necesaria en varios casos) sino el establecimiento de muchas formas de control público y ciudadano sobre estas producciones y distribuciones.

Redefinir el "Bien Común de la Humanidad" en función de otra definición de la economía es entonces una tarea necesaria frente a la destrucción del patrimonio común, como resultado del olvido de la dimensión colectiva de la producción de la vida y de la exclusividad del individualismo.

\section{Reorganizar la vida colectiva a través de la generalización de la democracia en las relaciones sociales y las instituciones}

Un tercer eje en la revisión de los fundamentos de la vida colectiva, en función del nuevo paradigma del Bien Común de la Humanidad está constituido por una generalización de la democracia, no solamente aplicada al sector político, sino también al sistema económico, en las relaciones entre hombres y mujeres, y en todas las instituciones. En otras palabras, la democracia formal, a menudo utilizada como una manera de establecer una igualdad artificial, reproduciendo de hecho desequilibrios sociales no reconocidos, debe transformarse en la formulación política de la solidaridad. Eso implica, en particular, una revisión del concepto del Estado y una reivindicación de los derechos humanos en todas sus dimensiones, individuales y colectivas. Se trata de hacer de cada ser humano, sin distinción de raza, sexo, o clase, un sujeto de la construcción social y así de revalorizar la subjetividad (Franz Hinkelammert, 2005).

La concepción del Estado es bastante central en este ámbito. El modelo de Estado jacobino, borrando todas las diferencias para construir ciudadanos en principio iguales, no basta para llegar a una verdadera democracia. Sin duda fue un paso adelante frente a las estructuras politicas del Antiguo régimen europeo. Hoy día no solamente se debe tener en cuenta las oposiciones de clase que permiten a una de ellas o a una coalición de estas, apoderarse de los aparatos del Estado para establecer la dominación de sus intereses, sino también las varias nacionalidades que constituyen un territorio y que tienen el derecho de reivindicar sus culturas, sus referencias territoriales, sus instituciones sociales. No se trata de caer en un comunitarismo debilitando al Estado, como en ciertos países europeos de la era neo-liberal, ni de regresar a un pasado romántico, como ciertos movimientos político-religiosos, ni de aceptar sin critica el neo-anarquismo de ciertas protestas legitimas y masivas, ni de caer en la trampa de los poderes económicos (empresas transnacionales o instituciones financieras internacionales) que prefieren negociar con entidades locales de pequeña dimensión. El objetivo es llegar a un equilibrio entre estas diversas dimensiones de la vida colectiva, internacionales, regionales, locales, reconociendo su existencia e instaurando mecanismos de participación.

El papel del Estado no puede ser concebido sin tener en cuenta la situación de los grupos sociales más marginalizados, los campesinos sin tierra, las castas inferiores y los dalits (fuera de castas) ignorados desde hace milenios, los pueblos indigenas de América y los afro-descendientes excluidos desde hace más de 500 años y en estos 
grupos, las mujeres a menudo doblemente marginalizadas. Procesos jurídicos, aún constitucionales, no bastan para cambiar la situación, aún si son útiles. El racismo y los prejuicios no desaparecen rápidamente en ninguna sociedad. En este sector el factor cultural tiene una importancia grande y puede ser el objeto de iniciativas especificas. Las politicas sociales, de protección contra las agresiones del mercado total y que permiten la satisfacción de las necesidades de base, constituyen un paso importante de la transición, a condición de no ser solamente asistencialistas y desvinculadas de reformas estructurales.

Es también importante señalar que ha habido una utilización de un vocabulario desviado de su sentido original. Las prácticas discursivas de la derecha son notables en esta materia. Se habla hoy, por ejemplo, de un "capitalismo verde". Pero aún en los países que quieren un cambio, el uso de conceptos tradicionales, a titulo de filosofia de base de las nuevas orientaciones, como el Sumak Kawsay, por ejemplo, debe ser medido en su sentido real, que puede ser elemento de una real transición a otro modo de existencia colectiva, pero puede también transformarse en una adaptación del sistema existente. El contexto político general permitirá entenderlo y evaluarlo.

La generalización de la democracia vale también para el diálogo entre las instancias políticas y los movimientos sociales. La organización de instancias de consulta y de diálogo pertenecen a la misma concepción, respetando la autonomía mutua. E1 proyecto de un Consejo de movimientos sociales en la arquitectura general del ALBA es una tentativa original en este sentido. El concepto de sociedad civil a menudo utilizado para expresar esta democracia generalizda, no deja de ser ambiguo, porque es también el lugar de las luchas de clase: existen en realidad una sociedad civil de abajo y una de arriba y la utilización no calificada del término, permite muchas veces crear la confusión y presentar soluciones sociales que ignoran las diferencias de clase $^{5}$. Por otra parte, algunas formas de democracia participativa, como se encuentran en varios países latino-americanos, entran también en la misma lógica de democracia generalizada. Una independencia real de los diversos poderes ejecutivo, legislativo y judicial es una garantía de funcionamiento democrático normal. Un Estado democrático debe ser también laico, es decir sin la intervención de instituciones religiosas mayoritarias o no, en los órganos de poder del Estado. Al mismo tiempo es la base de la libertad religiosa. Eso no significa un Estado laicista, que no reconoce la dimensión pública del factor religioso (la dimensión ética social de la Teología de la Liberación, por ejemplo) ni tampoco, como fue el caso en países del "socialismo real", estableciendo el ateísmo como casi-religión de Estado.

Hay otras instituciones concernidas por el mismo principio. Nada menos democrático que el sistema económico capitalista, con la concentración del poder de decisión en pocas manos. Lo mismo vale para los medios de comunicación social y se aplica también a todas las instituciones sociales, sindicales, culturales, deportivas, religiosas.

Asociada con la democracia generalizada, está evidentemente la noción de noviolencia. Los conflictos tienen que resolverse en las comunidades humanas, desde la familia hasta el orden internacional, vía mecanismos no-violentos adecuados, formales o informales. Se debe distinguir entre ejercer la fuerza y utilizar la 
violencia. El concepto de "violencia legitima" utilizado por el sociólogo alemán Max Weber, es peligroso, porque llega a una justificación fácil, por ejemplo, de guerras recientes, como en Irak, en Afganistan o en Libia. Sin embargo, si la no-violencia es el principio, lo deseable y deseado, la situación real es la de un mundo violento. Las razones son casi siempre, la búsqueda de una hegemonía económica o política. En la historia moderna, la reproducción del capitalismo como sistema ha sido un factor preponderante, para la acumulación del capital interno (el complejo militaroindustrial), para asegurar el predominio de una nación sobre otra, finalmente para el control de los recursos naturales (petróleo y metales estratégicos). Los argumentos culturales y religiosos han sido, de manera consciente o no, legitimaciones ideológicas capaces de motivar pueblos y muchedumbres, a conflictos de naturaleza económica o politica. Fueron también armas inmateriales de grupos oprimidos buscando la justicia. Así, como las dictaduras, las guerras son el fracaso de la democracia y significan una ruptura con la búsqueda del Bien Común de la Humanidad. Hoy en día, con las tecnologías de muerte disponibles, no existen más guerras justas, sino las resistencias populares de los pueblos que se levantan, cuando toda salida democrática ha sido excluida. Solamente un análisis socio-político e histórico completo (holístico) puede dar cuenta de estas situaciones.

Politicas concretas tanto negativas como positivas resultan de estos principios. Dispositivos para luchar contra el racismo o la discriminación de sexo en varias materias entran en esta orientación. Lo mismo vale para los medios de comunicación masiva, prohibiendo, por ejemplo, su propiedad al capital financiero. Reglas de funcionamiento democrático (igualdad de los sexos, alternabilidad en los cargos, etc.) podrian constituir condiciones de reconocimiento público (y eventualmente de subsidio) de instituciones no estatales, como partidos politicos, organizaciones sociales, ONGs e instituciones culturales y religiosas.

Para la política internacional, las aplicaciones son múltiples. Se piensa evidentemente en la ONU, donde varios componentes, para empezar, el Consejo de Seguridad, son muy poco democráticos. Igualmente sucede con los órganos de Bretton Woods, en particular el Banco Mundial y el Fondo Monetario Internacional. Apoyar los esfuerzos en este sentido puede ser una prioridad para los gobiernos de la periferia. El funcionamiento informal, pero con grandes poderes reales, del G8 o aún del G20, deben ser cuestionados. Las Cortes de Justicia para el respeto de los Derechos humanos, que son órganos deseables, tienen que ser sometidos a las mismas normas de democracia y nuevos campos de aplicación, como los crimines económicos, las deudas odiosas y los daños a la naturaleza tendrán de ser promovidos. Todas las nuevas instituciones regionales latinoamericanas, como el Banco del Sur, (la moneda) la unidad de valor para el intercambio regional SUCRE, el Alba, serán objeto de una atención particular en el sentido de generalización de la democracia y lo mismo vale para los otros continentes.

La destrucción de la democracia por el capitalismo, especialmente en su fase neo-liberal, ha sido tal, que las sociedades, a todos los niveles, se organizan en función de las ventajas de una minoría, provocando un grado de desigualdad en el mundo, nunca antes visto en la historia humana. Restablecer un funcionamiento 
democrático como paradigma universal constituye entonces un pilar del Bien Común de la Humanidad.

\section{Instaurar la interculturalidad en la construcción del Bien Común universal.}

Dar a todos los saberes, todas las culturas, las filosofias, las religiones, la posibilidad de contribuir al Bien Común de la Humanidad, es el objetivo de la revisión de este fundamento cultural. Éste no puede ser papel exclusivo de la cultura occidental que en realidad está actualmente identificada con la concepción de desarrollo, eliminando o marginalizando todas las otras perspectivas. Se debe descolonizar el imaginario ${ }^{6}$. Eso implica una lectura de la realidad, su interpretación o su anticipación como la ética necesaria para la elaboración del Bien Común de la Humanidad, la dimensión afectiva necesaria para la auto-implicación de los actores y las expresiones estéticas y prácticas. La pluriculturalidad integra, por supuesto, la adopción de las nuevas orientaciones de los tres otros fundamentos, (sobre) la relación con la naturaleza, la producción de las bases de la vida y la organización democrática generalizada. Ella es también importante para la trasmisión de las ideas y valores en los pueblos. Hablar en el lenguaje de cada uno y expresarse en términos culturalmente comprensibles es una exigencia de la democracia.

Sin embargo, no basta la multiculturalidad. Se trata de la promoción de una interculturalidad abierta, es decir de culturas en diálogo, con posibles intercambios. Las culturas no son objetos de museo, sino elementos vivos de una sociedad. Las migraciones internas y externas, vinculadas con el desarrollo de los medios de comunicación, son factores de muchos cambios culturales, evidentemente no todos deseados. Para existir, las culturas necesitan bases y medios materiales, como un territorio de referencia (bajo diversas modalidades), medios de educación y de comunicación, expresiones diversas como fiestas, peregrinajes, rituales, agentes religiosos, edificios, etc.

Esto nos lleva a los aspectos prácticos, como la organización del Estado pluricultural, lo que en países como Bolivia o el Ecuador se ha traducido en las constituciones como Estados plurinacionales, no sin dificultades de aplicación del concepto en la práctica. La idea central es la obligación del Estado de garantizar las bases de la reproducción cultural de pueblos diferentes y en particular asegurar su defensa contra las agresiones de la modernidad económica y de la hegemonía cultural. Por eso, la educación bilingüe es un instrumento privilegiado. Pero la noción de interculturalidad debe tener también un impacto sobre la educación general, como la enseñanza de la historia y la trasformación de una filosofia educacional orientada por la lógica del mercado. La publicación de libros a precio reducido, la organización de ferias del libro, de centros artesanales, de museos interactivos, etc. son instrumentos útiles. Los medios de comunicación son importantes porque trasmiten valores y no solamente informaciones, sin negar la pluralidad, ni la democracia. Este problema debe ser pensado en su conjunto, para promover las culturas locales, contrabalancear los monopolios y destrozar la dominación de un puñado de agencias internacionales. También instancias éticas deben tener la posibilidad de expresarse, como organismos de Defensa de los Derechos humanos, observatorios de diversos tipos, instituciones religiosas. 
La cultura incluye una dimensión espiritual, propia del ser humano, que lo lleva más allá de lo cotidiano. Este tema es central en un tiempo de crisis civilizatoria. Existe en el mundo entero una búsqueda de sentido, por la necesidad de redefinir las metas mismas de la vida. La espiritualidad es la fuerza que transciende la materia y da a esta un sentido. Las fuentes de espiritualidad son numerosas y se sitúan siempre al interior de un contexto social y no pueden existir sin una base física y biológica. El ser humano es uno: su espiritualidad presupone la materia y su materialidad no tiene sentido sin el espíritu. Una visión culturalista de la espiritualidad, que ignora la materialidad del ser humano, es decir el cuerpo para el individuo y la realidad económico-política para la sociedad, es una desviación conceptual, que lleva al reduccionismo (la cultura como único factor de cambio) o a la alienación (la ignorancia de las estructuras sociales). La espiritualidad, con o sin una referencia a algo sobrenatural, da un sentido a la vida humana en el planeta. $\mathrm{Su}$ traducción concreta está condicionada por las relaciones sociales de cada sociedad, pero al mismo tiempo ella puede dar una orientación a estas últimas. Un cambio de paradigma no se realizará sin espiritualidad, según múltiples caminos y numerosas expresiones.

La visión del mundo, la lectura de la realidad y su análisis, la ética de la construcción social y política, las expresiones estéticas y la auto-implicación de los actores, son partes esenciales de la elaboración de alternativas al modelo de desarrollo capitalista y de la civilización que este último trasmite. Ellas forman parte de todas las orientaciones nuevas de los fundamentos en función del paradigma alternativo, tanto de la relación con la naturaleza, como de la producción de las bases de la vida y de la redefinición de la economía, y finalmente de la manera de concebir la organización colectiva y política de las sociedades. Pueden en sus diversidades contribuir al cambio necesario para la supervivencia de la humanidad y del planeta, a la definición del nuevo paradigma del Bien Común de la Humanidad.

\section{Conclusiones.}

\section{El Bien Común de la Humanidad como objetivo global.}

De todo lo dicho anteriormente, se concluye que el Bien Común de la Humanidad es el fruto de una adecuada realización del conjunto de los cuatro ejes fundamentales de la vida colectiva de los seres humanos en el planeta. Tal como están definidos por el capitalismo, garantizados por las fuerzas politicas y trasmitidos por la cultura dominante, no son sostenibles y entonces no pueden asegurar el Bien Común de la Humanidad. Al contrario, sus aplicaciones contradicen la reproducción de la vida (François Houtart, 2009). Se necesitan cambios de paradigmas para permitir una simbiosis entre los seres humanos y la naturaleza, un acceso de todos a los bienes y servicios, una participación de cada sujeto individual y colectivo en los procesos organizativos sociales y políticos y la posibilidad de expresiones culturales y éticas propias, es decir para realizar el Bien Común de la Humanidad. Su realización es un proceso, generalmente largo, de tipo dialéctico y no lineal y fruto de muchas luchas sociales. El concepto, tal como se entiende en este trabajo, va más allá de la concepción clásica, griega, retomada por el Renacimiento (José Sánchez Parga, 
2005, 378-386) y también por la Doctrina social de la Iglesia Católica, basada en la filosofia de Tomas de Aquino.

Por eso éste necesita una revisión teórica, por una parte retomando la crítica de todos los elementos que llevaron al mundo a una situación sistémica de crisis con el agotamiento de un modelo histórico, y por otra parte, redefiniendo los objetivos de una construcción social nueva, respetuosa de la naturaleza y capaz de asegurar la vida humana como una edificación común. Como dice Enrique Dussel (2006), lo que se debe asegurar es la producción, la reproducción y el desarrollo de la vida humana de cada sujeto ético (cada ser humano). Es eso el Bien Común de la Humanidad. La última referencia del paradigma del desarrollo histórico de la humanidad es la vida en su realidad concreta, incluida la relación con la naturaleza, lo que está de hecho negado por el capitalismo.

Se podría objetar que eso es una utopía. Además del hecho que los seres humanos necesitan utopias y que el capitalismo ha destruido el pensamiento utópico, anunciando el fin de la historia (no hay alternativas), se puede afirmar que la búsqueda del Bien Común de la Humanidad es bien una utopía, no en el sentido de una ilusión, sino de lo que no existe hoy, pero que puede existir mañana. Al mismo tiempo, la utopía conserva también una dimensión dinámica: siempre habrá un mañana. Todo régimen político o movimiento religioso que pretende ser la utopía realizada, termina en catástrofe. Se trata de un llamado a caminar ${ }^{7}$. En este sentido, no se trata de "una utopía inofensiva" ( Evelyne Pieiller, 2011, 27). Eso se comprueba con los centenares de miles de movimientos sociales, de organizaciones de ciudadanos, de grupos políticos, que cada uno en su lugar específico, luchan por mejores relaciones con la naturaleza y por su protección, por una agricultura campesina y orgánica, por una economía social, la abolición de las deudas ilícitas, la apropiación colectiva de los medios de producción, la primacía del trabajo sobre el capital, la defensa de los derechos humanos, por una democracia participativa y por la valorización de las culturas. Los Foros Sociales Mundiales permiten visualizar esta realidad, lo que crea progresivamente una nueva consciencia social global.

Sin embargo, es un proceso dinámico que necesita una visión de conjunto coherente, como base de una convergencia en la acción, con el fin de construir una fuerza capaz de revertir el sistema dominante contemporáneo tanto en sus dimensiones económicas, como sociales, culturales y politicas. Es precisamente eso lo que quiere expresar el concepto de "Bien Común de la Humanidad": una coherencia teórica que reúne los cuatro ejes de la vida colectiva en el planeta y una visión que permite a cada uno de los movimientos y de las iniciativas sociales y políticas, ubicarse en el conjunto. Su elaboración no puede ser solamente el trabajo de algunos intelectuales que piensan por los otros, sino una obra colectiva, utilizando el pensamiento del pasado, especialmente la tradición socialista más directamente confrontada con el capitalismo e integrando elementos nuevos. Su difusión tampoco puede ser la responsabilidad exclusiva de una organización social o de un partido de vanguardia que monopoliza la verdad, sino de una pluralidad de fuerzas anti-sistémicas que luchan por el Bien Común de la Humanidad. Sin duda, muchas cuestiones teóricas y estratégicas quedan por ser estudiadas, discutidas y experimentadas. 


\section{La transición.}

No podemos entrar en más detalles en este escrito, sin embargo, vale la pena introducir otra noción en este momento de la reflexión. Se trata del concepto de transición. Carlos Marx lo desarrolló a propósito del pasaje del modo de producción feudal al capitalismo en Europa y Maurice Godelier lo resume de la manera siguiente: es "la fase particular de una sociedad que encuentra más y más dificultades en reproducir el sistema económico y social en el cual ella se funda y empieza a reorganizarse sobre la base de otro sistema que se trasforma en la forma general de las nuevas condiciones de existencia" (Maurice Godelier, 1982, 1165). Se trata evidentemente de procesos largos, no lineales, más o menos violentos de acuerdo con las resistencias de los grupos sociales involucrados. Muchos analistas estiman que el capitalismo ha llegado al fin de su papel histórico, porque se ha vuelto un sistema destructor de las propias bases de su éxito, como lo decía ya Carlos Marx, la naturaleza y el trabajo. Es así que Samir Amin habla del "capitalismo senil"; que Immanuel Wallerstein publicó un artículo en medio de la crisis financiera diciendo que se asiste al "fin del capitalismo" y que István Mészarós habla de la incapacidad de este sistema para asegurar el mantenimiento del "metabolismo social de la humanidad" $(2008,84)$.

Si por una parte, se puede aceptar la idea de que estamos viviendo una transición del modo de producción capitalista a otra forma de producción y que el proceso puede ser precipitado por la crisis climática, por otra parte, no se debe olvidar que un tal cambio será el resultado de un proceso social y que no puede realizarse sin luchas ni una transformación de las relaciones de fuerza. En otras palabras, el capitalismo no caerá por sí solo y la convergencia de todas las luchas sociales y politicas es un requisito para llegar a un resultado. La historia nos enseña que el capitalismo es capaz de transformar sus propias contradicciones en un aporte al proceso de acumulación. Ya se habla de un "capitalismo verde". La elaboración teórica del concepto en el contexto histórico de la crisis sistémica actual permitirá la elaboración de instrumentos de evaluación de las experiencias sociales y políticas en curso. Es particularmente el caso en América Latina con los regimenes que empezaron procesos de cambio y que se declaran forjadores del Socialismo del Siglo XXI.

El concepto puede también ser aplicado a procesos particulares dentro de la evolución general. En todo caso se trata, sin perder la radicalidad de los objetivos, de definir las acciones que pueden conducir al resultado (otro paradigma de desarrollo humano) teniendo en cuenta las circunstancias concretas del desarrollo material, por una parte y de las relaciones de fuerza existentes en los campos económicosocial y político, por otra. Un ejemplo típico son las economías de extracción, que a pesar de ser dañinas ecológica y socialmente y de estar dominadas ampliamente por los interés del capital, no pueden ser detenidas de un día para el otro en los países que, en América Latina, empezaron cambios importantes, porque, entre otras razones, constituyen la fuente financiera de las nuevas politicas. Es el caso de Venezuela y de Bolivia. La transición consistiria (1) en iniciar una politica económica basada en las necesidades del mercado interior (lo que es a largo y mediano paso), (2) en promover leyes ecológicas y sociales más estrictas con las explotaciones ecológicas y sociales, (3) hacer pagar sus costos a los usuarios y (4) 
promover una legislación internacional para evitar el fenómeno de las "ventajas comparativas" a favor de los que aplican regulaciones más laxas. En otros países menos implicados todavía en estas actividades, como el Ecuador, se podría pensar en una moratoria de algunos meses o años, para negociar las modalidades de una transición con los movimientos sociales.

La utilización de este instrumento conceptual no puede servir de pretexto para concesiones políticas o ideológicas de tipo social-demócrata, es decir aceptando que el desarrollo de las fuerzas de producción exige la adopción de principios, herramientas y recetas del capitalismo. Eso significa reforzar el poder de las clases sociales más opuestas a un cambio de modelo, como es el caso del Brasil, a pesar de sus avances en otros ámbitos; o crear, como en países socialistas, nuevas diferencias sociales que inevitablemente alargarán un proceso de transición, tal como en China o en el Vietnam. Esto plantea un problema fundamental: ¿cómo desarrollar las fuerzas productivas en una perspectiva socialista, es decir en función del Bien Común de la Humanidad y qué fuerzas desarrollar prioritariamente? Es un problema que los países socialistas y los regimenes progresistas que nacieron luego de la segunda guerra mundial, no pudieron resolver adecuadamente y que fue el origen, tanto de los fracasos, como de la orientación neo-liberal de la mayoría de ellos. Como lo decía Maurice Godelier en sus cursos en la Universidad Católica de Lovaina: "El drama del socialismo es que ha tenido que aprender a caminar con los pies del capitalismo". Desarrollar la agricultura campesina orgánica, como lo propuso un seminario asiático en la Universidad de Renmin en Beijing en 2010, en vez de promover los monocultivos de una agricultura agro-exportadora; reorganizar la red de ferrocarriles locales en América Latina, en vez de adoptar los proyectos del IIRSA (la iniciativa para la integración de las infraestructuras y de la energía, en América del Sur), son ejemplos que se podrian proponer. Muchos otros podrian ser pensados como elementos de una verdadera transición que no sea una simple adaptación del sistema.

\section{Por una Declaración Universal del Bien Común de la Humanidad.}

Otra función del concepto de Bien Común de la Humanidad sería la preparación de una Declaración Universal, en el cuadro de las Naciones Unidas. Evidentemente, no es una declaración que va cambiar el mundo, sino la organización de las fuerzas de cambio en torno a un proyecto en permanente elaboración. Esta Declaración podría ser un instrumento pedagógico útil, tanto para promover el necesario esfuerzo teórico, cuanto para la activación de los movimientos. Sería paralela a la Declaración Universal de los Derechos Humanos, que fue el resultado de un largo proceso cultural y político iniciado desde el Siglo de las Luces y el inicio de la "modernidad" y que significó la emancipación del individuo y el reconocimiento de sus derechos. Fue desarrollada por la Declaración de los Derechos Humanos en Francia y en los Estados Unidos de América, a finales del siglo XVIII. Sabemos que no es perfecta, que fue elaborada en un contexto muy influido por la visión social de la burguesia occidental, provocando reacciones como La Carta Africana de Derechos Humanos de la OEA y una iniciativa similar en el mundo árabe; sabemos también que ha sido utilizada por potencias occidentales para establecer su hegemonía en el planeta. Pero existe, ha salvado la libertad y aun la vida de 
muchas personas y ha orientado muchas decisiones útiles por el bien del género humano. La Declaración Universal de los Derechos Humanos mejoró con el tiempo, agregando nuevas dimensiones de derechos de segunda o tercera generación. Sin embargo, para afrontar los peligros que corren el planeta y el género humano, un nuevo proyecto es necesario, que exija no solamente una ampliación de los derechos humanos, sino una redefinición del Bien Común de la Humanidad. (sobre la base de nuevos paradigmas.)

Así, la preparación de una nueva Declaración Universal puede ser instrumento de una movilización social y politica, para crear una nueva conciencia y servir de base a la convergencia de los movimientos sociales y politicos en el plano internacional. Es evidentemente una tarea a largo plazo, pero que exige un comienzo. La convergencia de movimientos sociales, como el Foro Social Mundial o de partidos políticos como el Foro de São Paulo, no solamente pueden contribuir a promover tal Declaración, sino también los países de manera individual en organismos internacionales como la UNESCO o en la misma ONU. Va a ser una lucha politica, pero que vale la pena y que puede inscribirse como uno de los elementos simbólicos de la revolución necesaria para redefinir el paradigma alternativo de la vida colectiva de la humanidad en el planeta.

Vincular la defensa de los "Bienes comunes" como el agua y la visión de la nueva construcción del "Bien Común de la Humanidad" es pues importante, porque por una parte la visión holística que supone este último concepto exige implantaciones concretas, como la de los "bienes comunes", para salir de lo abstracto y traducirse en acciones. Por otra parte, las luchas particulares deben también inscribirse en un conjunto, a fin de situar adecuadamente el papel que están jugando, no simplemente para paliar las deficiencias de un sistema cuya existencia se trata de prolongar, sino de una trasformación profunda que exija la convergencia de todas las fuerzas de cambio para establecer las bases de la supervivencia de la 
humanidad y del planeta.

\section{REFERENCIAS BIBLIOGRÁFICAS.}

Acosta a. \& Martínez, E. (2009). El Buen Vivir - Una vía para el desarrollo, Quito, Abya Yala.

Albo X. Suma Qamaña. (2010). Convivir Bien, ¿Cómo medirlo?. Diálogos, Año 1 No. $0,54-64$.

Amin S. (2003). Le capitalisme et la nouvelle question agraire, Dakar, Forum du Tiers Monde.

Beinstein J. (2009). El largo Crepúsculo del capitalismo, Buenos Aires, Cartago. Boff L. (2000). El despertar del Águila, Madrid, Ed. Trotta.

Braudel F. (1969). Écrits sur 1’Histoire, Paris, Flammarion.

Brie M. (2011). Making the Common Good of Humanity concrete, contribución a la Conferencia de la Fundación Rosa Luxemburgo, De los "bienes comunes" al "Bien Común de la humanidad", Roma.

Carcanholo R.A. \& Sabadini M.de S. (2009). Capital ficticio y ganancias ficticias, en Dierckxsens W. et AL.

Delgado G. (2011). Bienes Comunes, Metabolismo social y el Futuro común de la Humanidad: Un Análisis Norte-Sur, contribución a la Conferencia de la Fundación Rosa Luxemburgo: De los "Bienes comunes" al "Bien Común de la Humanidad", Roma.

De Souza Santos B. (2010). Refundación del estado en América Latina - perspectivas desde una epistemología del Sur, Quito, Abya Yala.

De Schutter O. (2011). Eco-farming can doubble Food production, Geneva, Office of ghe High Commissioner for Human Rights.

Dussel, E. (2006). Etica de la liberación en la edad de la globalización y de la exclusión. Madrid, Trotta.

Dierckxsens W. et Alt. (2009). La gran crisis del siglo XXI - Causas, carácter, Perspectivas, san José, DEI.

Dierckxsens W. et AL. (2010). Siglo XXI, Crisis de una Civilización, San José, DEI.

Dierckxsens W. (2011). Población, Fuerza de Trabajo y rebelión en el Siglo XXI, 
texto preparado para el taller del Foro mundial de Alternativas en el Foro Social Mundial de Dakar, www. Forumalternatives. Org.

Echeverria B. (2001). Las Ilusiones de la Modernidad, Quito, Trama social.

Fornet-Betancourt R. (2011). La Philosophie interculturelle - Penser autrement le Monde, Paris, Les Editions de l'Atelier.

George S. (2005). Le rapport Lugano, Paris, Fayart.

Godelier M. (1982). Transition, in Dictionnaire critique du Marxisme, Paris, PUF.

Gudynas E. (2009). El mandato ecológico - derechos de la Naturaleza y políticas ambientales en la nueva Constitución, Quito, Abya Yala.

Herrera R. (2008). Un autre Capitalisme est possible, Paris, Syllepse.

Herrera R. \& Nakatani P. (2009). Las Crisis financieras, Raíces, Razones, Perspectivas, et AL., 2009, .in DIERKRXSENS et AL.

Herrera R. (2011). Réflexions sur la Crise et ses Effets, contribución a la Conferencia de la Fundación Rosa Luxemburgo: "De los "Bienes comunes" al "Bien Común de la Humanidad", Roma.

Hinkelammert F. (2006). El Sujeto y la Ley. El retorno del sujeto oprimido. Caracas, El Perro y la Rana.

Houtart F. (2010). La Agro-energía, Solución para el Clima o Salida de Crisis para el capital, Panamá, Ruth casa Editorial, La Habana, Ediciones Sociales.

Kovel J. (2007). The Ennemy of Nature - The End of capitalism or the End of the World, Londres, Nueva York, Zed Books.

Latouche S. (2010). Sortir de la Société de Consommation - Les Biens qui libèrent, Paris.

Lemoine M. (2011). A quoi sert 1'Utopie?, Recension de Eduardo Galeano, Le Monde Diplomatique.

Maffesoli. (1988). Le Temps des Tribus, Paris. Méridiens Klincksiek.

Mercier-Jesa S. (1982). Besoin, in Bensussan G. y Labica G., Dictionnaire critique du Marxisme, Paris, PUF, 96-100.

Meszaros I. (2008). El Desafio y la Carga del Tiempo histórico - El Socialismo del Siglo XXI, Buenos Aires, CLACSO, Caracas, Vadell. 
Molina Moline E. (2010). Vigencia de la Teoría general de Keynes, La Habana, Ed. De Ciencias Sociales.

Nunez O. (2011). La Economía Social Solidaria en las naciones Proletarizadas y el Proletariado por Cuenta propia en la transformación del Sistema, Managua, CTPC-FNT.

Ortega J. (1995). Identidad y Posmodernidad en América latina, Socialismo y Paricipación, $\mathrm{N}^{\circ} 70$.

Pettella R. (1988). Le Bien Commun - Eloge de la Solidarité, Bruxelles, Labor.

Pieiller E. (2011), Dans la caverne de Alain Badiou, Le monde Diplomatique.

Pleyers G. (2010). Alterglobalization - Becoming Actors in the Globs Age, Cambridge, The Polity Press.

Quiroga D. (2009). Sumak kawsai, Hacia un nuevo pacto en harmonía con la Naturaleza, en Acosta A. et AL.

Ruiz de Elvira M. (2010). El "Gran hermano de los Barcos, El País. España.

Salamanca Serrano, A. (2011). Teoría Socialista del Derecho. Quito, Ed. Jurídica del Ecuador.

South center. (2008). food autosufficiency and energy crisis. Ginebra.

Stern N. (2006). Report on the Economy of Climate Change. Londres, Finance Ministry.

Sternkell. Z. (2010). Anti-Lumières de tous les pays. Le Monde Diplomatique, Décembre 2010, 3.

Vandepitte M. (2011). Redirecting production for life's necessities, prioritizing Use Value over Exchange Value, contribución a la Conferencia de la Fundación Rosa Luxemburgo: De los "Bienes comunes" al "Bien Común de la Humanidad", Roma.

Wallerstein I. (2000). Globalization or The Age of Transition ? - A Long Term View of the Trajectory of the World System, International Sociology, Vol.15 (2), 251267. 


\section{Notas:}

1 Texto presentado en la Conferencia "De los bienes comunes al Bien Común de la Humanidad", organizada por la Fundación Rosa Luxemburgo, en Roma (28 y 29 abril 2011) y revisado después de las discusiones. Este texto sirvió también de base para un documento escrito para el Instituto de Altos Estudios Nacionales del Ecuador (Quito).

2 Los "commons" eran tierras comunales de las poblaciones campesinas en Inglaterra, que poco a poco, a partir del siglo XIII se transformaron en propiedades privadas de terratenientes por medio del proceso de "enclosures", es decir de clausuras establecidas por ellos, especialmente para la ganadería de borregos, lo que provocó numerosas revueltas campesinas.

3 El "agente naranja", utilizado durante la guerra de Vietnam para destruir las selvas donde combatía la guerrilla del Sur, causa aún 40 años después, muchos daños y afecta a miles de niños que nacen discapacitados debido a la acumulación de productos químicos.

4 Se estima que el $70 \%$ del trabajo en el mundo es informal, lo que dificulta la organización de los trabajadores. Sin embargo, varios ensayos existen hoy dia, como en Nicaragua, la Confederación de los Trabajadores por Cuenta propia (CTCPFNT), afiliada a la Federación Nacional de los trabajadores de Nicaragua (FNT) у a Streetnet Internacional (Orlando Nuñez, 2011).

5 En un barrio pobre de Bogotá, había hace algunos años una inscripción sobre una pared "Nosotros también tenemos Derechos Humanos".

6 Ver Raúl Fornet, 2011).

7 Eduardo Galeano escribe a propósito: "Me acerco dos pasos , ella se aparta dos pasos. Avanzo diez pasos y el horizonte se escapa diez pasos más lejos. Yo podría siempre avanzar y nunca la alcanzaré. Para qué sirve la utopía ¿precisamente para eso; para caminar" (Maurice Lemoine, 2010). 